\title{
Seismic Analysis of 10-MW Off Shore Wind Turbine with Large-Diameter Monopile in Consideration of Seabed Liquefaction
}

\section{Jian Zhang}

The Hong Kong Polytechnic University

Songye Zhu ( $\square$ ceszhu@polyu.edu.hk)

The Hong Kong Polytechnic University https://orcid.org/0000-0002-2617-3378

\section{Guo-Kai Yuan}

China Energy Engineering Group Guangdong Electric Power Design Institute

\section{Quan Gu}

Xiamen University

\section{Shitang Ke}

Nanjing University of Aeronautics and Astronautics

Ai-Guo Pei

China Energy Engineering Group Guangdong Electric Power Design Institute

\section{Research Article}

Keywords: offshore wind turbines, liquefaction potential, excess pore water pressure, bending moment envelop

Posted Date: June 16th, 2021

DOl: https://doi.org/10.21203/rs.3.rs-596968/v1

License: (9) This work is licensed under a Creative Commons Attribution 4.0 International License. Read Full License 


\section{large-diameter monopile in consideration of seabed liquefaction}

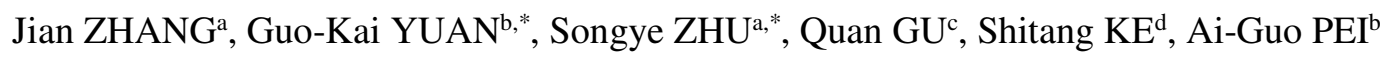

${ }^{a}$ Department of Civil and Environmental Engineering, The Hong Kong Polytechnic University, Hong

5 Kong, China

$6{ }^{\mathrm{b}}$ China Energy Engineering Group Guangdong Electric Power Design Institute Co. Ltd., Guangzhou,

7 Guangdong Province, China

$8 \quad{ }^{\mathrm{c}}$ School of Architecture and Civil Engineering, Xiamen University, Xiamen, China

$9{ }^{\mathrm{d}}$ Department of Civil Engineering, Nanjing University of Aeronautics and Astronautics, Nanjing,

10 China

\section{ABSTRACT}

With the increasing construction of large-scale wind turbines in seismically active coastal areas, the survivability of these high-rated power offshore wind turbines (OWTs) in marine and geological conditions becomes extremely important. Although research on the dynamic behaviors of OWTs under earthquakes has been conducted in consideration of soil-structure interaction, attention paid to the impact of earthquake-induced seabed liquefaction on OWTs supported by large-diameter monopiles is limited. In view of this research gap, this study carries out dynamic analyses of a 10-MW OWT under the combined wind, wave, and earthquake loadings. This study uses a pressure-dependent multi-surface elastoplastic constitutive model to simulate the soil liquefaction phenomenon. Results indicate that the motion of the large-diameter monopile leads to more extensive soil liquefaction surrounding the monopile, specifically in the zone near the pile toe. Moreover, compared with earthquake loading alone, liquefaction becomes more severe under the coupled wind and earthquake loadings. Accordingly, the dynamic responses of the OWT are apparently amplified, demonstrating the importance of considering the coupling loadings. Compared with wind loading, the effect of wave loading on the dynamic response and liquefaction potential is relatively insignificant.

Keywords: offshore wind turbines, liquefaction potential, excess pore water pressure, bending moment envelop

"Corresponding author: Prof. Songye Zhu, Email: songye.zhu@polyu.edu.hk 


\section{Introduction}

The contradiction between the plan to increase energy consumption and reduce the carbon footprint has motivated many countries to explore more sustainable and renewable energy sources, including wind, solar, hydropower, geothermal, and biomass. In the past several decades, wind energy has rapidly developed worldwide since the oil crisis in the early 1970s. Moreover, many onshore and offshore wind farms have been constructed or are being planned, specifically in Europe, the United States, and Asia. Fig. 1 presents the development history of the total installation of wind turbines (WTs) in the world. The accumulated wind power capacity reached approximately $651 \mathrm{GW}$ in 2019 , with $28.9 \mathrm{GW}$ for offshore WTs, accounting for $4.5 \%$ of the total capacity (GWEC 2020).

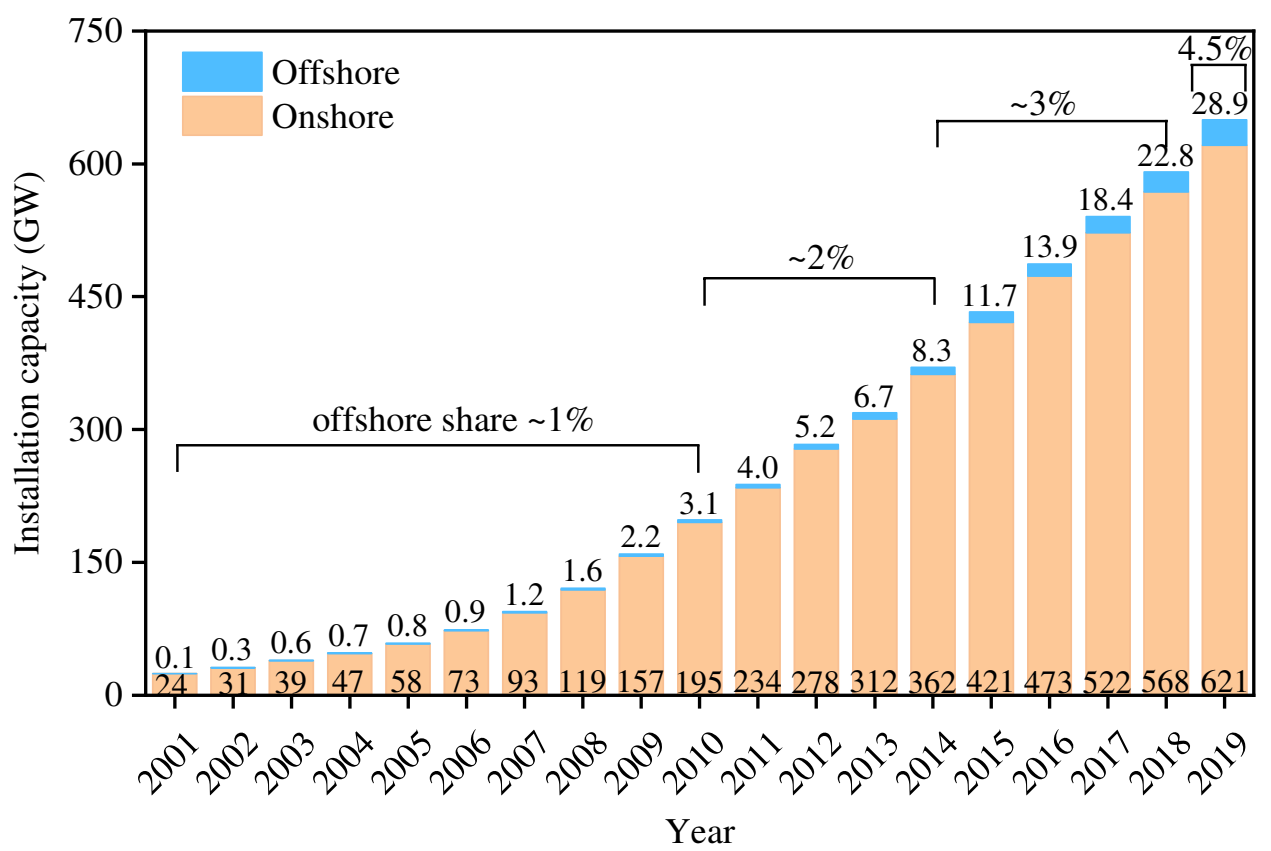

Fig. 1 Development history of a total installation of WTs (onshore and offshore) (GWEC 2020)

Several distinct trends are witnessed in the current WT market. The first is the increasing installation of WTs in the coastal area (Bento and Fontes 2019; Watson et al. 2019). Offshore wind turbines (OWTs) have become mainstream due to their inherent advantages, such as higher and steadier wind speed, adequate installation space, and less visual and noise impacts. The second one is the extensive construction of wind farms in the seismic-prone areas because of the larger population size and energy requirement in these specific zones, such as China, Japan, and India (Katsanos et al. 2016; Kaynia 2019). The third one is the energy capture improvement by using increasingly large turbine structures (Veers et al. 2019). For example, the most powerful WT prototype, that is, the GE 12-MW Halidae-X, has recently produced the first power at the Rotterdam-Maasvlakte port in the 
51 Netherlands (OffshoreWIND 2019). The last one is the use of various foundation types for 52 bottom-fixed and floating OWTs, of which monopiles are still the most common choice due to their 53 simpler shape, easier installation, and better economic benefits (Igwemezie et al. 2019; Negro et al. 2014; Oh et al. 2018; Wang et al. 2018b; Wu et al. 2019).

Given these development trends, high-power OWTs that are supported by large-diameter monopiles in active seismic zones present new design requirements and challenges. For example, based on wind field data in 38 years (from 1979 to 2016), Wan et al. (2018) investigated the wind energy potential of the South China Sea (Fig. 2a). They concluded that the climatic and geographic circumstances in Taiwan Strait are highly favorable for wind power development. The average wind power density of Taiwan Strait reaches approximately $450 \mathrm{~W} / \mathrm{m}^{2}$ because of the monsoon influence and strait narrowing effect. Numerous wind plants have been planned or constructed, such as the Xinghua Bay Wind Farm and Chang-Bin Wind Farm. Meanwhile, the strait is located between the Eurasian Plate and the Philippine Sea Plate and represents a region with the highest seismicity (Li et al. 2020), as depicted in Fig. 2b). Therefore, the new installations will be susceptible to coupled wind, wave, and earthquake loadings.
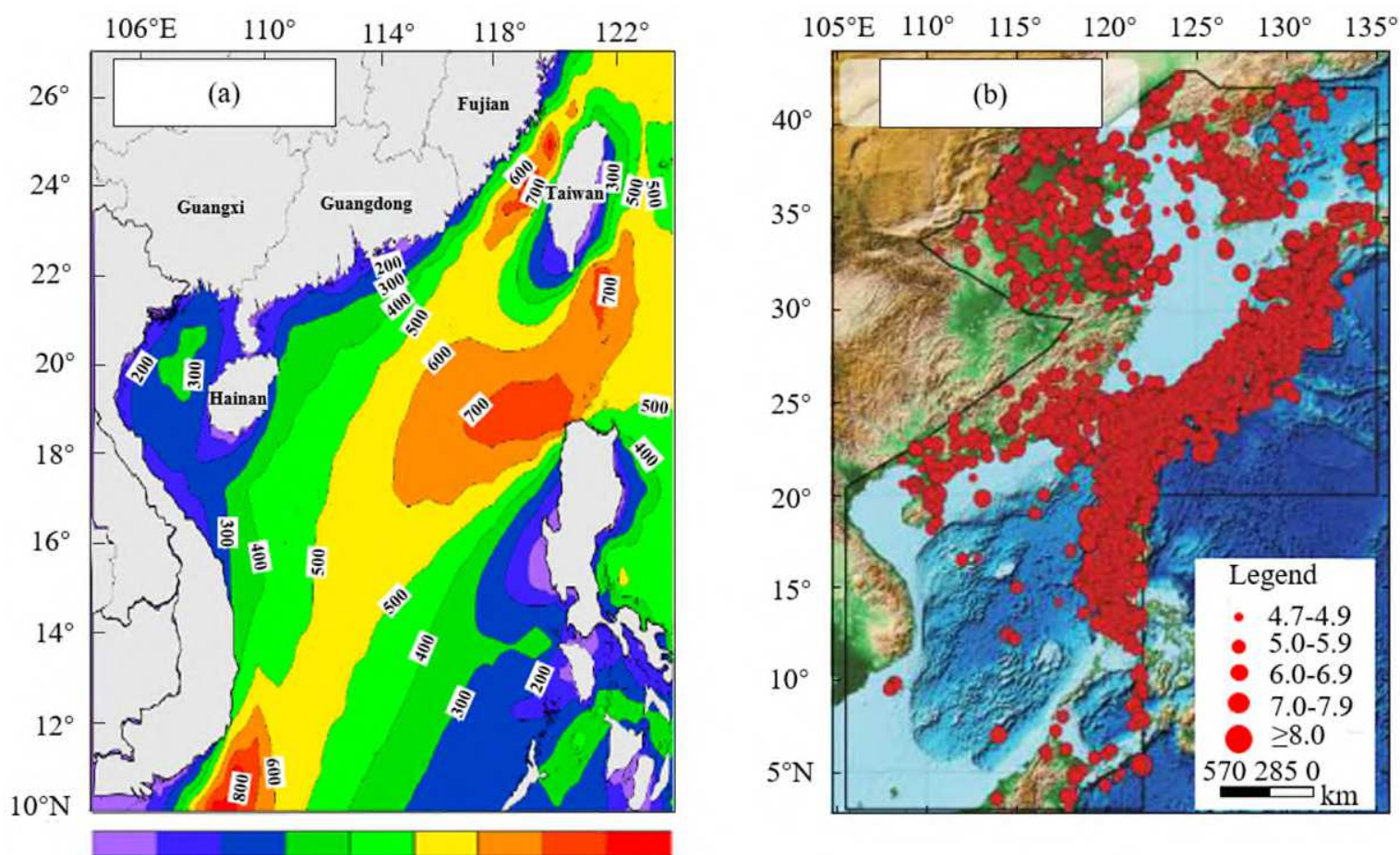

$\begin{array}{llllllllll}0 & 100 & 200 & 300 & 400 & 500 & 600 & 700 & 800 & \mathrm{~W} / \mathrm{m}^{2}\end{array}$

Fig. 2 Wind power and earthquake distribution in the South China Sea: (a) the average wind power density (1979-2016) (Wan et al. 2018) and (b) seismic epicenter distribution (BC1767-2018) (Li et al. 2020) 
The existing research on WTs subjected to seismic loadings mainly includes three aspects. The first is the dynamic responses of onshore WTs under wind and earthquake loadings or offshore WTs under the wind, wave, and earthquake loading in consideration of aerodynamic damping, seismic loading conditions and types (Alati et al. 2015; Huang et al. 2021; Kjørlaug and Kaynia 2015; Patil et al. 2016; Santangelo et al. 2018; Santangelo et al. 2016; Sigurðsson et al. 2020; Yang et al. 2018; Zafeirakos and Gerolymos 2013). Then, the second is the fragility analysis and collapse evaluation employing the nonlinear incremental dynamic analysis approach to assess the exceeding probability for various damage states (Asareh et al. 2016; Fan et al. 2019; Kim et al. 2014; Martín del Campo and Pozos-Estrada 2020; Quilligan et al. 2012). Last, the third is the frequency variation and dynamic performance considering the soil-structure interaction (SSI) by employing three conventional simplified models, namely, apparent fixity, coupled springs, and distributed springs (Damgaard et al. 2014; Wang et al. 2021; Wang et al. 2018a; Yang et al. 2019a; Yang et al. 2019b; Zuo et al. 2019).

A general conclusion that seismic loading on WTs is insignificant compared with wind loadings has been drawn in the literature (Prowell and Veers 2009). However, this conclusion needs to be carefully revisited, particularly for OWTs, given that the liquefaction risk has often been overlooked in the aforementioned literature. The geotechnical investigation of the Chang-Bin Wind Farms (Kuo et al. 2020; Wang et al. 2016b) pointed out that the seabed was mainly composed of silty sand and low plasticity clay, with loose to medium sand existing in the upper 25-m layer. Standard penetration tests clarified that the liquefaction thickness was more than $15 \mathrm{~m}$. Earthquake-induced liquefaction was observed during numerous strong earthquakes, such as 1964 Niigata (Japan), 1964 Alaska (USA), 1999 Chichi (Taiwan), 1999 Kocaeli (Turkey), 2008 Wenchuan (China), and 2011 Christchurch (New Zealand) (Xiang et al. 2019). Field investigation, laboratory tests, and numerical simulations have been conducted to evaluate liquefaction potential and possible consequences. These studies include initial liquefaction, pore water pressure generation, soil lateral spreading and settlement, and pile bending moment variation (Sumer et al. 2007). When coupled with considerable wind and wave loading, ground liquefaction may pose a potential risk to irreversible permanent deflection or even structural stability, which certainly warrants due research attention.

Despite significant effects on a single pile-soil system, liquefaction evaluation studies for OWTs remain limited. Barari et al. (2017) employed the University of California, San Diego (UCSD) sand model to investigate small monopile-supported OWTs under cyclic loads with different cycle numbers 
and frequencies. Using the same soil model, Patra and Haldar (2018) further examined the influence of various loadings on liquefaction by considering an artificial seismic record. Kementzetzidis et al. (2019) adopted the SANISAND04 model to investigate the geotechnical dynamics of an 8-MW OWT with a monopile foundation under coupled wind and wave loadings. For other types of foundation, Zhang et al. (2014a; 2014b) analyzed seismic response and anti-liquefaction performance of WTs with a prestressed concrete bucket foundation by using the Seed simplified method (Seed and Idriss 1970; Shanon and Wilson 1976) and different finite element (FE) software (e.g., ADINA and ABAQUS). Esfeh and Kaynia (2019) also conducted liquefaction assessment for a floating WT, which was fixed on the seabed with the anchor pile and anchor suction using the finite-difference code, FLAC3D, and Kobe-L seismic records. Wang et al. (2017), Li et al. (2021), and Wang et al. (2020) carried out a series of geotechnical centrifuge tests of the newly developed suction bucket and hybrid monopile foundations in dry and saturated soil conditions. Then they evaluated the liquefaction resistance effectiveness of these foundations based on the soil seismic behavior and superstructure dynamic response.

However, some questions remain unanswered in the literature. First, numerous simulations and experiments were focused on a small-diameter monopile. However, the soil-pile interaction and liquefaction mechanism for high-rated power OWTs supported by large-diameter piles have not been systematically investigated. Second, with the increasing rotor diameter and hub height, the wind loading plays a more critical role in the ultimate limit state and serviceability limit state design. The coupling of wind, wave, and earthquake loadings under different operating conditions may influence the liquefaction depth, which has not been discussed so far. This study aims to answer these fundamental questions by employing the DTU 10-MW benchmark WT model supported on a monopile with a large diameter of $10 \mathrm{~m}$. The detailed FE model was established in the software OpenSees using an advanced soil constitutive model to capture the variation of excess pore water pressure (EPP) and liquefaction depth. Three loading scenarios, including five earthquake records, instantaneous wind loading with earthquake records, and wind-wave-earthquake coupling loading, were simulated.

This study is organized into five sections. Following the introduction in Section 1, Section 2 presents the numerical modeling of the DTU 10-MW WT. This section also introduces a multi-surface constitutive model describing the effective soil stress and the damping model considering the 
structural and loading characteristics. Section 3 describes the earthquake, wind, and wave loadings and the corresponding modeling procedure concisely. Section 4 focuses on liquefaction development and dynamic response by comparing soil and pile performance in different loading scenarios. Section 5 concludes the study and summarizes the findings.

\section{Numerical modeling of OWT}

\subsection{DTU 10-MW reference WT}

Two reference WT models, namely, National Renewable Energy Laboratory (NREL) 5-MW WT and Technical University of Denmark (DTU) 10-MW WT, are commonly employed to assess the dynamic performance of OWTs under complex environmental loadings. To reduce the levelized cost of energy, the rated power is continuously enhanced by increasing the blade length and tower height. Given this development trend, the DTU 10-MW OWT with a large-diameter monopile foundation proposed by Bak et al. (2013) and Velarde (2016) is selected as an example in this study. The outer diameter of the tower varies linearly from $8.3 \mathrm{~m}$ at the bottom to $5.5 \mathrm{~m}$ at the top. The tower is divided into ten sections, where the wall thickness of each section is assumed to be constant. Meanwhile, Velarde (2016) suggested that the tower diameter of each section should be increased with the same factor of 1.25 to satisfy the fundamental frequency requirement of the entire system, whereas the wall thicknesses are kept unchanged. The total length of the monopile is $75 \mathrm{~m}$, of which $40 \mathrm{~m}$ is in seawater and $35 \mathrm{~m}$ is embedded into the seabed. The monopile diameter is $10 \mathrm{~m}$, and the wall thickness is assumed to be $1 / 80$ of the monopile diameter, approximately $0.125 \mathrm{~m}$.

\subsection{Structural modeling}

The complete three-dimensional FE model is built using an open-source FE code OpenSees (Version 2.5.0) for seismic simulations, as shown in Fig. 3. The rotor-nacelle assembly (RNA) fixed at the top of the tower is represented by lumped mass points to simplify the computation. The transition piece (TP) is also modeled as a lumped mass attached to the tower node with a height of $19.0 \mathrm{~m}$ above sea level. Table 1 shows that the masses of the rotor, nacelle, and TP are 227,962, 446,036, and $500,000 \mathrm{~kg}$, respectively. The tower density is assumed to be $8,500 \mathrm{~kg} / \mathrm{m}^{3}$ in consideration of the paint, welds, bolts, and flanges, whereas the monopile density embedded into the soil is considered as 7,885 $\mathrm{kg} / \mathrm{m}^{3}$. Tower and monopile are modeled by the nonlinear beam-column element with 12 degrees of freedom (DOFs), and they are divided into 129 and 47 elements, respectively, with an element size of 


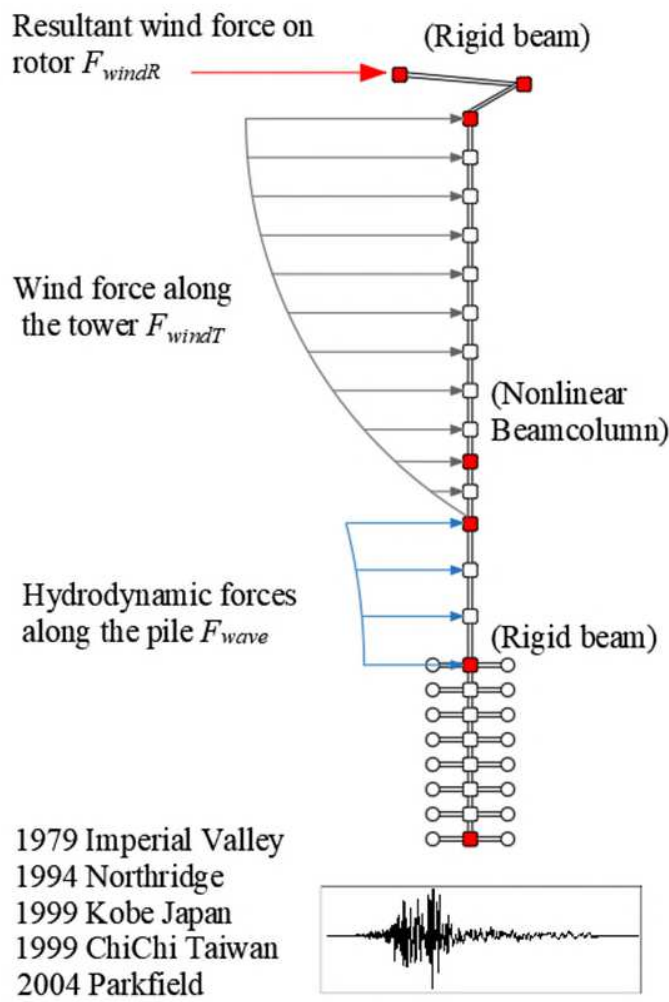

161

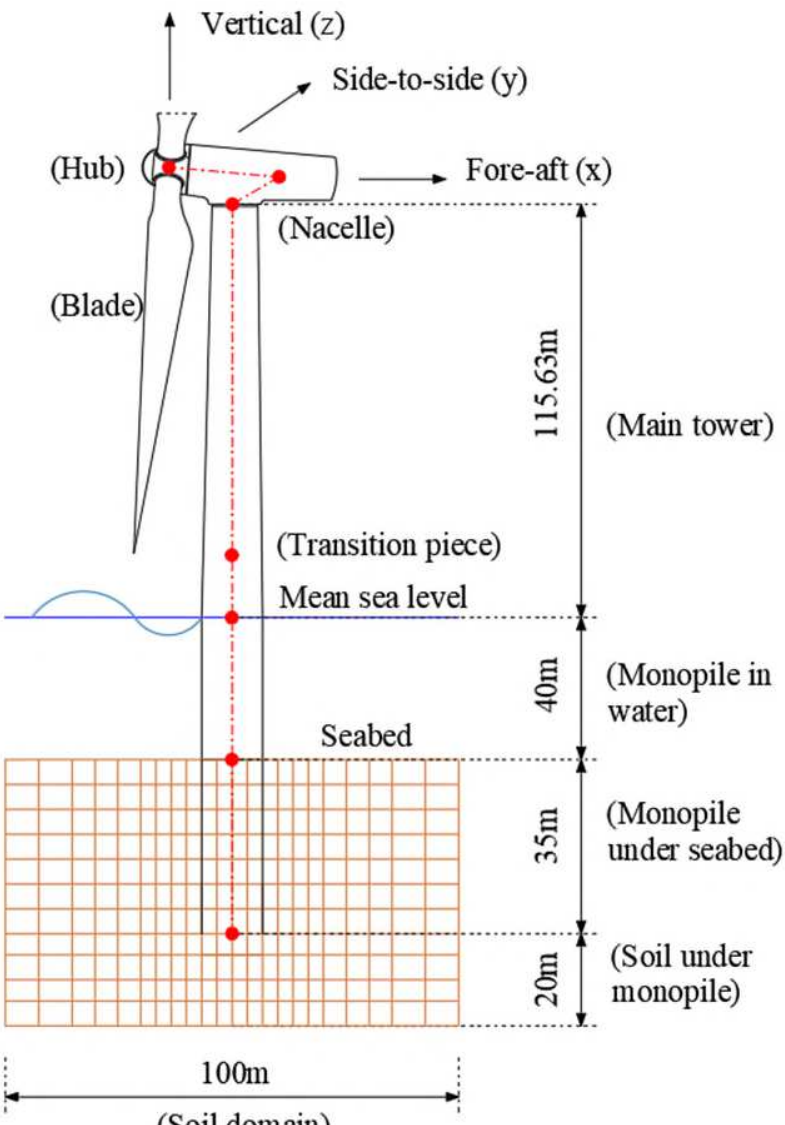

(Soil domain)

Fig. 3 Schematic representation of the OWT model and environmental loading

The vibration of the monopile in seawater would accelerate the surrounding water, and the watermonopile interaction can be modeled by using the added mass approach, as suggested by De Risi et al. (2018) and Dong (1978). The tributary mass is only valid in the horizontal translational direction. The effective mass, $m_{e}$, on the monopile nodes in water can be expressed as

$$
\begin{gathered}
m_{e}=m_{\text {monopile }}+m_{\text {add }}, \\
m_{\text {add }}=C_{a} A_{p} \rho_{w},
\end{gathered}
$$

where $m_{\text {monopile }}$ is the physical mass of monopile and $m_{\text {add }}$ is the added mass, $C_{a}$ is the added mass coefficient, which is assumed to be 1.0 as suggested in (DNVGL 2017), $A_{p}$ is the cross-section of monopile, and $\rho_{w}=1030 \mathrm{~kg} / \mathrm{m}^{3}$ is the seawater density. 
172 Main parameters of the FE model (Bak et al. 2013; Velarde 2016)

\begin{tabular}{|c|c|c|}
\hline \multicolumn{3}{|c|}{ DTU 10-MW reference WT with large-diameter monopile } \\
\hline \multirow[t]{3}{*}{ Basic description } & Rated power & $10 \mathrm{MW}$ \\
\hline & Cut-in, rated, cut-out wind speed & $4 \mathrm{~m} / \mathrm{s}, 11.4 \mathrm{~m} / \mathrm{s}, 25 \mathrm{~m} / \mathrm{s}$ \\
\hline & Minimum, maximum rotor speed & $6.0 \mathrm{rpm}, 9.6 \mathrm{rpm}$ \\
\hline Rotor-nacelle & Single blade mass & $40,699 \mathrm{~kg}$ \\
\hline \multirow[t]{3}{*}{ assembly } & Hub mass & $105,520 \mathrm{~kg}$ \\
\hline & Nacelle mass & $446,036 \mathrm{~kg}$ \\
\hline & Blade structural damping ratio & $0.48 \%$ \\
\hline \multirow[t]{6}{*}{ Tower } & Height above water & $115.63 \mathrm{~m}$ \\
\hline & Tower diameter & $10.375 \mathrm{~m}$ (bottom), $6.875 \mathrm{~m}$ (top) \\
\hline & Wall thickness (10 sections from & $0.038 \mathrm{~m}, 0.036 \mathrm{~m}, 0.032 \mathrm{~m}, 0.034 \mathrm{~m}, 0.030 \mathrm{~m}$, \\
\hline & bottom to top) & $0.028 \mathrm{~m}, 0.026 \mathrm{~m}, 0.024 \mathrm{~m}, 0.022 \mathrm{~m}, 0.020 \mathrm{~m}$ \\
\hline & Integrated mass & $786,223 \mathrm{~kg}$ \\
\hline & Structural damping ratio & $1 \%$ \\
\hline Transition piece & Integrated mass & $500,000 \mathrm{~kg}$ \\
\hline \multirow[t]{5}{*}{ Monopile } & Length & $40 \mathrm{~m}$ (in water); $35 \mathrm{~m}$ (in soil) \\
\hline & Diameter & $10 \mathrm{~m}$ \\
\hline & Wall thickness & $0.125 \mathrm{~m}$ \\
\hline & Integrated mass & $2,554,000 \mathrm{~kg}$ \\
\hline & Structural damping ratio & $1 \%$ \\
\hline \multirow[t]{3}{*}{ Soil domain } & Length & $100 \mathrm{~m}$ \\
\hline & Width & $100 \mathrm{~m}$ \\
\hline & Depth & $55 \mathrm{~m}$ \\
\hline
\end{tabular}
models (e.g., PressureDependMultiYield, PressureDependMultiYield02,

\subsection{Soil Modeling}

Adopting nonlinear springs, as recommended in ISO 19901-4 (ISO 2016) and DNVGL-RP-C212 (DNVGL 2019) to model the soil domain, prevents the proper evaluation of the liquefaction risk. The nonlinear p-y method is a widely adopted model in the studies of SSI of OWTs. Although this method could be extended to the dynamic analysis of foundations in liquefiable soil by considering the dynamically evolved soil properties, this approach cannot capture pore water pressure. Therefore, three-dimensional finite element/finite difference (FE/FD) approaches are widely employed for liquefaction evaluation with appropriate soil constitutive models. Lu et al. (2011) and Qiu et al. (2019) summarized several advanced soil constitutive models, including pressure-independent models (e.g., PressureDependMultiYield03, and LadeDuncanMultiYield). These models were developed in the 
185 UCSD based on multi-surface models suggested by Prevost (1977; 1985). They presented the model 186 applications in some typical pile-supported multi-span bridges and wharves. Then, Zhang et al. (2018) 187 employed this elastic-perfectly plastic model to study the effects of peak ground velocity on the 188 pile-soil system's response on a liquefiable site. Cheng and Jeremić (2009) adopted the boundary surface model presented by Dafalias and Manzari (2004) and Manzari and Dafalias (1997) and u-p-U constitutive formulation to validate its effectiveness for liquefaction analysis. Rahmani and Pak (2012) further demonstrated the efficiency of this model by comparing the numerical results and experimental outcomes by Wilson (1998). Based on the concept of reversible and irreversible components of volumetric strain, Wang et al. $(2014 ; 2016 \mathrm{a})$ constructed two Tsinghua sand models,

194 which were employed to simulate the pre- and post-liquefaction phenomenon for the single and group pile foundation in the liquefied soil. Considering the inconsistent stress distribution and scaling similarity problems in the shake table and centrifuge tests, numerical simulation is still regarded as the predominant choice for liquefaction assessment on a full-scale prototype.

198 The UCSD constitutive model (i.e., the PressureDependentMultiYield material in OpenSees) is 199 employed in this study to describe soil liquefaction (Elgamala et al. 2002; Yang et al. 2008). Fig. 4 200 shows the schematic of the constitutive model. In this constitutive model, plasticity is formulated 201 based on the multi-surface concept (Drucker-Prager type) with a non-associative flow rule to reproduce the dilatancy effect. The model parameters for saturated medium sand suggested by Yang et al. (2008) are employed in this study considering the aforementioned geotechnical reports of the

204 Chang-Bin Wind Farm. Table 2 presents the corresponding model parameters of the adopted medium 205 sand. 
(a)
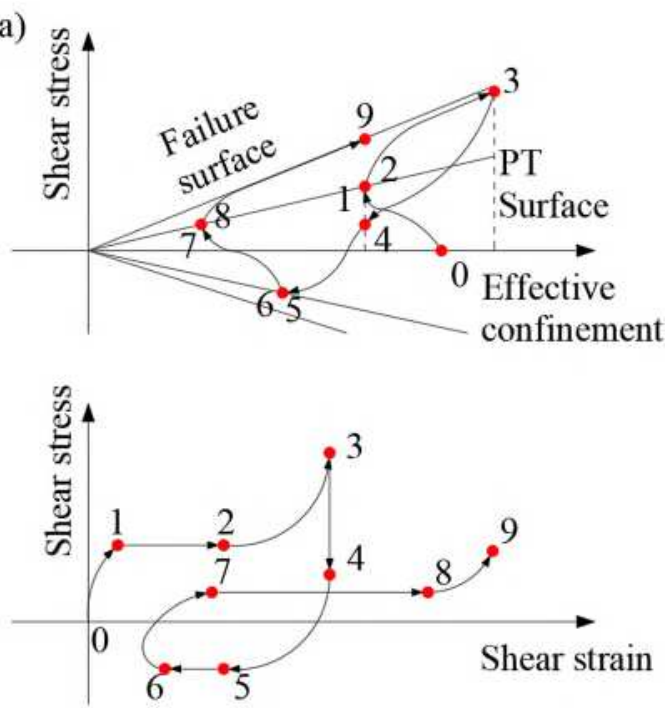

\section{Table 2}

Model parameters of medium sand (Yang et al. 2008) (b)

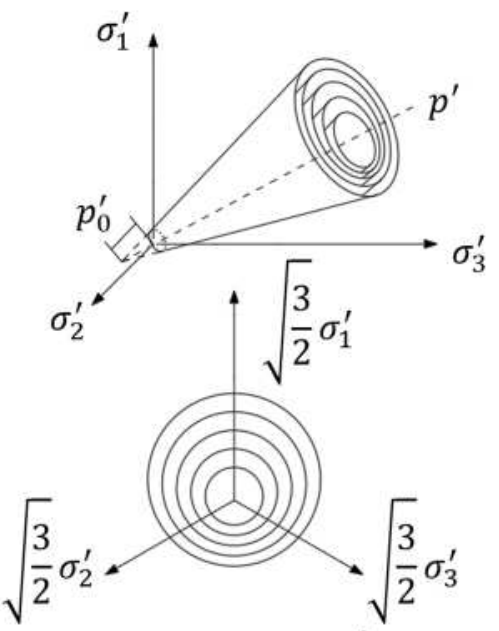

$\sigma^{\prime}$ : effective Cauchy stress tensor; $p^{\prime}$ : mean effective stress; $p_{0}^{\prime}$ : a smaller positive constant for numerical convenience

Fig. 4 Constitutive model of PressureDependentMultiYield material (Yang et al. 2008): (a) schematic of the constitutive model and (b) conical yield surfaces in principal stress space and deviatoric plane

\begin{tabular}{ll}
\hline Parameters & Values \\
\hline Relative density & $35 \%-65 \%$ \\
Saturated soil mass density $\left(\mathrm{kg} / \mathrm{m}^{3}\right)$ & 1,900 \\
Reference low-strain shear modulus $(\mathrm{kPa})$ & 75,000 \\
Reference bulk modulus $(\mathrm{kPa})$ & 200,000 \\
Friction angle (in degrees) & 33 \\
Peak shear strain at peak shear strength (-) & 0.1 \\
Reference mean effective confining pressure $(\mathrm{kPa})$ & 80 \\
Constant defining various shear and bulk modulus & 0.5 \\
Phase transformation angle (in degrees) & 27 \\
Constant defining the rate of shear-induced volume contraction or pore pressure built up & 0.07 \\
Constant 1 defining the rate of shear-induced volume dilation & 0.4 \\
Constant 2 defining the rate of shear-induced volume dilation & 2 \\
Parameter 1 controlling the mechanism of liquefaction-induced perfectly plastic shear strain & 10 \\
accumulation (kPa) & \\
Parameter 2 controlling the mechanism of liquefaction-induced perfectly plastic shear strain & 0.01 \\
accumulation & \\
Parameter 3 controlling the mechanism of liquefaction-induced perfectly plastic shear strain & 1 \\
accumulation & \\
Number of yield surfaces & 20 \\
Initial void ratio & 0.6 \\
Numerical constant & 0.7 \\
\hline
\end{tabular}

As shown in Fig. 3 and Table 1, the length and width of the soil domain are assumed to be $100 \mathrm{~m}$, 
212 which is ten times the monopile diameter, whereas the depth is $55 \mathrm{~m}$, approximately 1.5 times the pile

213 length. This depth is adopted per the suggestion of Barari et al. (2017) to achieve a good balance 214 between computing efficiency and accuracy. The soil domain is modeled by eight-node BrickUP 215 elements with four DOFs for each node, wherein DOFs 1-3 are for node displacements and DOF 4 is 216 for fluid pressure. The mesh size in the vertical direction is set to $5.0 \mathrm{~m}$, whereas different mesh sizes $217(2.5,5.0$, and $10.0 \mathrm{~m})$ are adopted in the horizontal direction, as suggested by Chiaramonte et al. 218 (2013). Fig. 3 shows the detailed mesh information, where fine and coarse meshes are used in the 219 domains close to and far from the monopiles, respectively. A simplified approach, the rigid 220 beam-column links (radially rigid "spikes") connecting the pile and soil nodes, is employed to model the interaction between the monopile and surrounding soil. This method was initially adopted by Law and Lam (2001) to a large pile group and then expanded by Elgamal et al. (2008) to simulate and evaluate the seismic response and liquefaction potential of the Humboldt Bay Bridge. The monopile and rigid link nodes are connected directly to the surrounding soil nodes by using the EqualDOF command for translations only.

This paper mainly focuses on the scenario when various dynamic loads are applied in the same direction, which is regarded as the most critical scenario as briefly explained in Section 4.1. Considering the symmetry of the model and loads, only half of the system is modeled in this scenario to improve computational efficiency. All DOFs of the meshes at the bottom boundary are restrained, representing the bedrock layer. The displacements within the symmetry plane are free, whereas the component normal to the symmetry plane is restrained. The horizontal DOFs of soil nodes on two-side boundaries are tied together on the same level. In particular, the static water pressure caused by $40-\mathrm{m}$ seawater is also considered and added to DOF 4 of soil nodes on the seabed surface. Transformation is adopted for the Constraint Handle in OpenSees, and SparseSYM and ProfileSPD are selected for the System of Equations in the nonlinear dynamic and eigenvalue analysis, respectively.

\subsection{Modal properties}

238 Eigenvalue analyses are conducted to examine the dynamic properties (i.e., modal frequencies and mode shapes) of the OWT system. The obtained modes 1,2 , and 6 with the frequencies of 0.287 , 1.256, and $3.091 \mathrm{~Hz}$ are corresponding to the first, second, and third tower fore-aft frequencies, respectively. The first frequency is slightly higher than the value of $0.25 \mathrm{~Hz}$ reported by Velarde 
242 (Velarde 2016). The discrepancy may be attributed to different SSI simulation approaches. The

243 simulated fundamental frequency in this study still lies in between the rotational frequency range 1P

$244(0.104-0.167 \mathrm{~Hz})$ and blade passing frequency range, $3 \mathrm{P}(0.312-0.501 \mathrm{~Hz})$.

\section{2.5. System damping}

246 The damping mechanism of an OWT is quite complicated. The damping usually comprises 247 structural, aerodynamic, hydrodynamic, and soil damping, which accounts for the contributions of the superstructure, wind, wave, and current, and soil, respectively. Aerodynamic damping results from the interaction between the wind and rotating blades and varies with operational conditions. In the parked state, the blades are pitched to the maximum pitch angle, and the aerodynamic damping is minimal and negligible. By contrast, the aerodynamic damping is high in normal operating conditions. The aerodynamic damping ratio in the fore-aft direction for an in-operation WT is generally in the range of 1\%-6\% (Valamanesh and Myers 2014). Hydrodynamic damping develops from the drag between the monopile and surrounding water, which includes radiation and viscous damping. The upper values of radiation and viscous damping ratios specified in Germanischer Lloyd are $0.22 \%$ and $0.15 \%$, respectively (Mo et al. 2017). The soil damping is from SSI, which consists of material and waves of radiation damping. In Zuo et al. (2018), wave radiation damping is neglected, and a constant of $1 \%$ of the soil damping ratio is adopted. Structural damping includes material damping and damping from vibration control systems. The material damping ratio of steel tower and monopile is suggested to be 0.33\% (Bak et al. 2013). The vibration control system is not introduced herein, and the corresponding ratio is not considered. If we sum all the above components, then the damping ratios of the OWT in parked and operating conditions are equal to $1.67 \%$ and $5.17 \%$, respectively. However, in the nonlinear response history analysis (RHA), such a direct superposition of the damping ratios would overestimate the total damping of the OWT system. As suggested by Ali et al. (2019) and De Risi et al. (2018), constant damping ratios of $1.5 \%$ and $3.0 \%$ are chosen for the parked and operating OWT, respectively, in this study.

267 Rayleigh damping is the most common model in the RHA, and the following equations could be adopted to estimate mass and stiffness coefficients:

$$
\begin{aligned}
& \alpha=2 \zeta \frac{\omega_{a} \omega_{b}}{\omega_{a}+\omega_{b}}, \\
& \beta=2 \zeta \frac{1}{\omega_{a}+\omega_{b}},
\end{aligned}
$$



consider excitation characteristics, where QUAD4M is a computer program to evaluate seismic responses of soil structures (Hudson et al. 1994).

274 Table 3

Selected earthquake records

\begin{tabular}{lllllll}
\hline No. & Year & Magnitude & Earthquake event & Station name & $\begin{array}{l}\text { PGA } \\
(\mathrm{g})\end{array}$ & $\begin{array}{l}\text { Predominant } \\
\text { frequency } \\
(\mathrm{Hz})\end{array}$ \\
\hline E1 & 1979 & 6.53 & Imperial Valley & El Centro Array \#11 & 0.38 & 3.78 \\
E2 & 1994 & 6.69 & Northbridge & Canyon Country-W Lost Canyon & 0.48 & 1.42 \\
E3 & 1995 & 6.90 & Kobe & Shin-Osaka & 0.23 & 0.81 \\
E4 & 1999 & 6.20 & Chi-Chi & CHY101 & 0.18 & 0.59 \\
E5 & 2004 & 6.00 & Parkfield & Parkfield - Froelich & 0.46 & 7.40 \\
\hline
\end{tabular}

\section{Dynamic loading cases}

In IEC 61400-3-1 (IEC 2019), five different types of loads should be included for the design calculation: (1) gravitational and inertial loads, including static and dynamic loads resulting from gravity, vibration, rotation, and earthquake; (2) aerodynamic loads, involving static and dynamic loads caused by the airflow and its interaction with the stationary and moving parts of WTs; (3) actuation load, resulting from the control system of WTs; (4) hydrodynamic loads caused by water flow and its interaction with the support structure; and (5) ice loads acting on the foundation. As this study focuses on the influence of earthquakes on the liquefaction risk, the dynamic complexity arising from the ice loads and control system (e.g., pitch and yaw system) is not included.

\subsection{Inertial loading}

As listed in Table 1, the structural weight is composed of the masses of different components, including the masses of RNA, tower, monopile, and transition section. In this study, the tower and monopile are assumed to interface at the mean sea level. The water surrounding the monopile is modeled by the added mass method with a coefficient of 1.0, as described in subsection 2.2. The soil domain is simulated by the continuum elements, in which the gravitational forces are added 
automatically in OpenSees.

292

\subsection{Wind loading}

The wind load along the tower is applied to the tower nodes in the x-direction. The thrust force imposed on the hub is extracted from the Fatigue, Aerodynamic, Structures, and Fatigue (FAST) code (Jonkman and Jr. 2005), which was developed by NREL in the US. A regular wind profile at a rated wind speed is considered, which is more likely to occur during the entire lifetime of WTs and is more realistic than storms and hurricanes when an earthquake occurs.

The wind action along the tower is proportional to the wind velocity profile, as described by the following formula in IEC 61400-3-1 (IEC 2019).

$$
v(z)=v_{\text {hub }}\left(\frac{z}{h_{\text {hub }}}\right)^{0.14},
$$

where $h_{h u b}$ is the height of the hub center measured from the sea surface, $v_{\text {hub }}$ is the velocity at the hub height and is assumed to be the rated wind speed (i.e., $11.4 \mathrm{~m} / \mathrm{s}$ ), and $z$ and $v(z)$ are the height and wind velocity of the concerned tower node, respectively. Then, the velocity could be employed to calculate the horizontal forces through the following equation:

$$
F_{\text {wind } T}(z)=0.5 \rho_{a} v^{2}(z) A(z),
$$

where $\rho_{a}$ is the air density, typically equal to $1.225 \mathrm{~kg} / \mathrm{m}^{3}$, and $A(z)$ is the tributary area.

Two methods are usually adopted to evaluate the resultant aerodynamic force. One is a simplified method considering the thrust coefficient. In this approach, Eqs. (6) and (7) could be employed to estimate this static force based on Frohboese et al. (2010) and Arany et al. (2017)

$$
\begin{gathered}
F_{\text {windR }}=0.5 C_{T} \rho_{a} v_{\text {hub }}^{2} A_{\text {swept }}, \\
C_{T}=\frac{3.5\left(2 V_{\text {hub }}+3.5\right)}{V_{\text {hub }}^{2}},
\end{gathered}
$$

where $C_{T}$ is the thrust coefficient, $\rho_{a}$ is the air density, $v_{h u b}$ is the velocity at the hub height, $A_{\text {swept }}$ is the rotor swept area, and $V_{h u b}$ is the rated wind speed.

The other is the blade element momentum (BEM) theory considering the appropriate wind speed information. This method incorporated in the FAST is adopted in the following simulation, wherein the Kaimal spectrum is employed to produce the wind field, and the BEM theory is utilized to 
313 calculate the aerodynamic loading along the blade. The Kaimal spectrum for three wind components $314(K=u, v$, and $w)$ (Jonkman and Buhl 2006) is shown below.

$$
\begin{gathered}
S_{K}(f)=\frac{4 \sigma_{K}^{2} L_{K} / \bar{u}_{h u b}}{\left(1+6 f L_{K} / \bar{u}_{h u b}\right)^{5 / 3},} \\
L_{K}=\left\{\begin{array}{l}
8.10 \Lambda_{U} K=u \\
2.70 \Lambda_{U} K=v \\
0.66 \Lambda_{U} K=w,
\end{array}\right. \\
\Lambda_{U}=0.7 * \min (60 \mathrm{~m}, H u b H t), \\
\sigma_{v}=0.8 \sigma_{u}, \quad \sigma_{w}=0.5 \sigma_{u},
\end{gathered}
$$

315 where $f$ is the wind frequency, $L_{K}$ is an integral scale parameter, $\bar{u}_{h u b}$ is the mean wind speed 316 corresponding to the hub height $\mathrm{HubHt}, \Lambda_{U}$ is the turbulence scale parameter, and $\sigma_{K}$ is the ambient turbulence standard deviation in three directions. In addition, the spatial coherence model is adopted to add the correlations between the same wind components at two spatially separated points. The IEC equations for the three components (Jonkman and Buhl 2006) shown below are considered.

$$
\begin{gathered}
C o h_{i, j K}=\exp \left(-a_{K} \sqrt{\left(\frac{f d}{\bar{u}_{h u b}}\right)^{2}+\left(b_{K} d\right)^{2}}\right), \\
a_{u}=12, b_{u}=\frac{0.12}{5.67 * \min (60 \mathrm{~m}, H u b H t)} \\
a_{v}=\text { large number, } b_{v}=0 \\
a_{w}=\text { large number, } b_{w}=0,
\end{gathered}
$$

where $f$ is the wind frequency, $d$ is the distance between two concerned spatial points $i$ and $j$, and $a_{K}$ and $b_{K}$ are the input coherence decrement and offset parameters. Following the constructed wind field, the local lift and drag force on each blade element could be computed using the BEM theory (Moriarty and Hansen 2005).

$$
\begin{gathered}
d F_{L}(r, t)=\frac{1}{2} \rho_{a} V_{r e l}^{2} c(r) C_{l}(\alpha) d r, \\
d F_{D}(r, t)=\frac{1}{2} \rho_{a} V_{r e l}^{2} c(r) C_{d}(\alpha) d r, \\
V_{r e l}(r, t)=\sqrt{\left(\left(V_{0}(r, t)(1-a)\right)+\stackrel{\circ}{w}(t)\right)^{2}+\left(\Omega r\left(1+a^{\prime}\right)\right)^{2}},
\end{gathered}
$$

where $r$ is the radial distance of the considered element from the center of the hub, $C_{l}(\alpha)$ and 
326 chord length. $V_{r e l}(r, t)$ is the relative wind velocity, defined according to the instantaneous wind

327 speed $V_{0}(r, t)$, the stochastic component of wind flow $\stackrel{\circ}{w}(t)$, and the rotation velocity $\Omega . a$ and $a^{\prime}$ are axial and tangential induction factors. Finally, the total blade force could be determined by the computational integration along the blade and consequently, the resultant aerodynamic force could also be defined. Fig. 5a shows the calculated resultant force-time history extracted from the FAST and the equivalent static force based on Frohboese's method at the hub. Given that the short duration of the selected seismic records is only $30 \mathrm{~s}$, only a short window (around $37 \mathrm{~s}$ ) of the wind loading is chosen for the dynamic analyses under the coupled loadings.
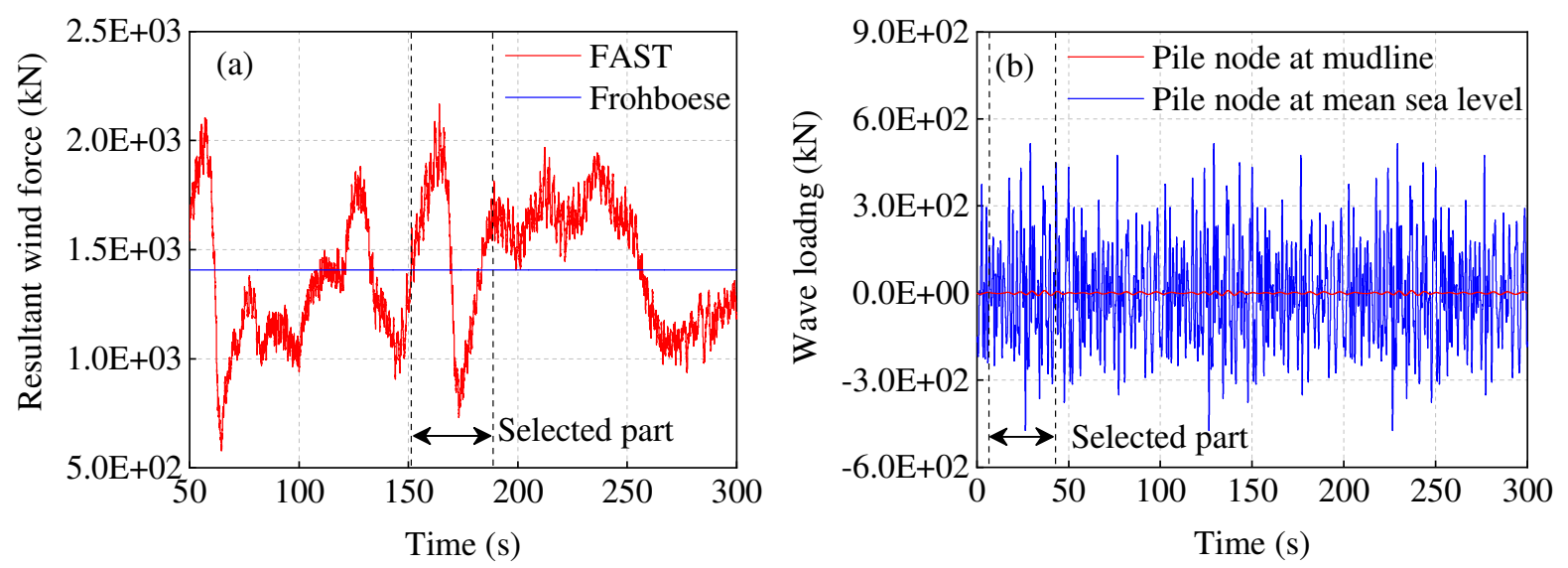

Fig. 5 Environment loading: (a) wind loading imposed at the hub; and (b) wave loadings on pile nodes

\subsection{Wave loading}

The wave load imposed on the monopile is also considered in this study. The power spectral density (PSD) of sea elevation can be described by the JONSWAP spectrum (DNV 2014).

$$
S(w)=a^{*} H_{s}^{2} \frac{w^{-5}}{w_{p}^{-4}} \exp \left(-\frac{5}{4}\left(\frac{w}{w_{p}}\right)^{-4}\right) \gamma^{\exp \left(\frac{\left(w-w_{p}\right)^{2}}{2 \tau^{2} w_{p}^{2}}\right),}
$$

where $\omega$ is the circular frequency in $\mathrm{rad} / \mathrm{s}, H_{s}$ is the significant wave height, $\omega_{p}$ is the peak wave 340 frequency, and parameter $a^{*}$ is calculated by

$$
a^{*}=\frac{0.0624}{0.230+0.0336 \gamma-0.185(1.9+\gamma)^{-1}},
$$


$\omega \leq \omega_{p}, \tau=0.07$; while $\tau=0.09$ for $\omega>\omega_{p}$. In the wave load simulation, the peak wave frequency and the significant wave height are adopted as $0.96 \mathrm{rad} / \mathrm{s}$ and $1.9 \mathrm{~m}$, respectively.

344 After the PSD of the sea surface elevation is determined, the sea surface elevation time history can 345 be simulated by using the inverse fast Fourier transform (IFFT) technique. Therefore, the 346 hydrodynamic load on each monopile element can be calculated by using the Morison formula (DNV 347 2014).

$$
\mathrm{d} F_{\text {wave }}=\frac{1}{2} \rho_{w} C_{D} D \mid d \& d z+\rho_{w} C_{M} \pi \frac{D^{2}}{4} d z
$$

348 where $\rho_{w}$ is the seawater density; $C_{D}$ and $C_{M}$ are the drag and inertia coefficient, respectively,

349 which are taken as 1.2 and 2.0, respectively, in this study; $\&$ and are the horizontal water particle velocity and acceleration, respectively; and $D$ is the outer diameter of the monopile. The monopile in the water is equally divided into 40 segments with a length of $1.0 \mathrm{~m}$ to simplify the calculation. The representative wave loads at the mean sea level and mudline are shown in Fig. 5 b.

\subsection{Earthquake loading}

The medium sand is considered to reproduce the liquefaction phenomenon, and its corresponding shear wave velocity is $198.7 \mathrm{~m} / \mathrm{s}$, which corresponds to the site class D defined in the ASCE 7-10 (ASCE 2010). Therefore, five earthquake records for site class D, denoted as E1 to E5, are selected, with their PGAs ranging from 0.18 to $0.48 \mathrm{~g}$. Table 3 presents the details of the selected strong ground motion records. Their PGAs are linearly scaled to $0.15 \mathrm{~g}$ to meet the requirement for the seismic precautionary intensity level of seven defined in GB 50010-2010 in China (MoHURD 2016). The dominant horizontal components of the strong motion records are inputted to the FE model in this study. Fig. 6 depicts the acceleration response spectra for a damping ratio of 3.0\%, wherein the damping ratio corresponds to an operating condition of OWT. The response spectra for the damping ratio (i.e., 1.5\%) in a parked state are not shown herein. All the peak frequencies of the five response spectra are considerably lower than the tower's first fore-aft frequency, but they are closer to the second or third fore-art frequencies of the tower. In particular, the Northridge earthquake shows two peaks close to the second and third fore-art frequencies. 


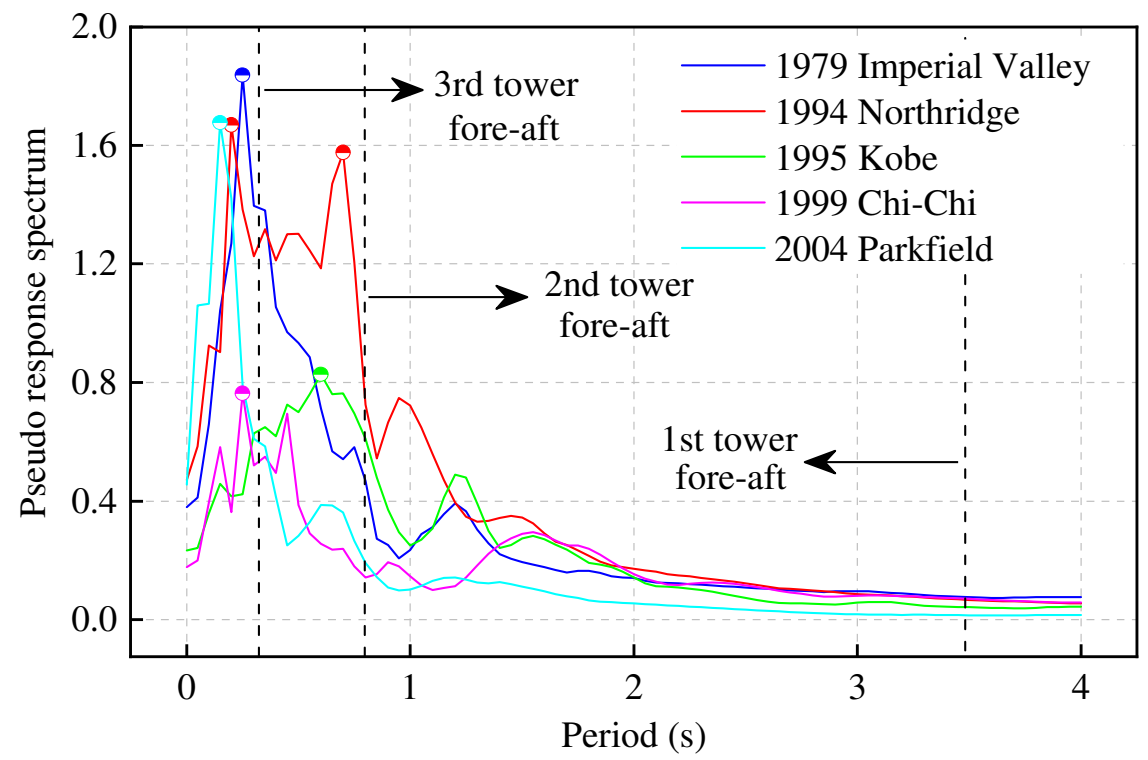

Fig. 6 Acceleration response spectra of five selected ground motion records (damping ratio $=3.0 \%$ )

\subsection{Simulated scenarios}

370 Four different scenarios are simulated, as shown in Table 4. In scenario 1, only the soil domain under the selected seismic records is simulated, whereas in scenario 2, the soil domain plus the OWT superstructure is simulated under the same seismic records. Furthermore, in scenario 3, the dynamic wind loading corresponding to the rated wind speed is further introduced to simulate the coupled effect of wind and earthquake loadings on the OWT. The wave load is supplemented in scenario 4. The simulation time is $5 \mathrm{~s}$ beyond the ground motion records to consider a dissipation time.

Table 4

Simulation scenarios for liquefaction evaluation for the OWT

\begin{tabular}{lllllll}
\hline \multirow{2}{*}{ Scenario } & Analysis object & $\begin{array}{l}\text { Wind } \\
\text { speeds } \\
(\mathrm{m} / \mathrm{s})\end{array}$ & Records & $\begin{array}{l}\text { PGA } \\
(\mathrm{g})\end{array}$ & $\begin{array}{l}\text { Turbine } \\
\text { states }\end{array}$ & Remarks \\
\cline { 4 - 6 } & & 0.0 & E1-E5 & 0.15 & - & Earthquake \\
Scenario 1 & Free-field soil & 0.0 & E1-E5 & 0.15 & Parked & Earthquake \\
Scenario 2 & OWT & 0.0 & E1-E5 & 0.15 & In-operation & Earthquake+Wind \\
Scenario 3 & OWT & 11.4 & E1-E5 & 0.15 & In-operation & Earthquake+Wind+Wave \\
Scenario 4 & OWT & 11.4 & & & &
\end{tabular}

379 A staged modeling procedure is employed to simulate the pile existence and generate accurate initial conditions for liquefaction assessment (Wang et al. 2016a). In the first stage, the soil domain without the pile is modeled by adopting the BrickUP elements with a significant permeability coefficient and tied boundary condition. An elastic gravity stage is initially carried out. Then, the state 
of soil is updated using the proposed plastic model to produce the initial effective stress in scenario 1 .

384 Next, the superstructure, monopile foundation, and links are introduced, and three translational DOFs

385 of the monopile and link nodes are tied to adjacent soil nodes. Another plastic gravity step is

386 conducted to account for the settlement and consolidation of soil caused by the pile and WT gravity and generate the proper initial stress for liquefaction evaluation in scenarios 2,3 , and 4 . After the gravity stages, the earthquake loading or the coupled loadings are applied. The soil permeability coefficient is updated with the appropriate value to simulate the undrained condition of the soil domain. Fig. 7 depicts the detailed procedure for scenarios 2, 3, and 4.

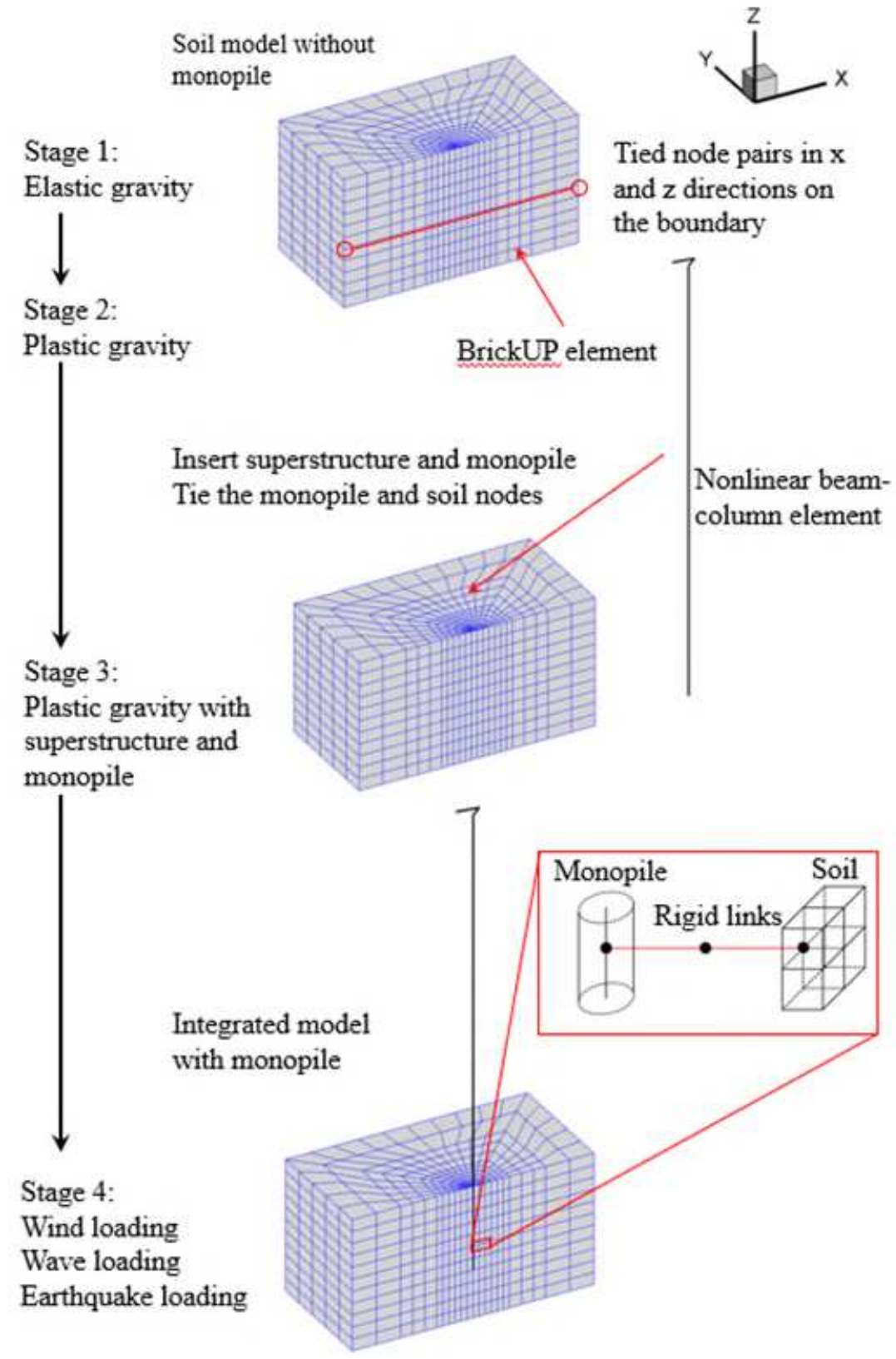

Fig. 7 Simulation procedure for the OWT system in liquefiable soil 


\section{Numerical Results and Discussions}

394 The pore water pressure is monitored at seven columns of soil points, including SP1×, SP2 $\times$, SP $3 \times$, SP4x, and SP5x on the left side (upwind) of the monopile and SP6x and SP7x on the right side (downwind) of the monopile, to assess the liquefaction possibility of the soil domain. The " $x$ " symbol represents the numbers $1-5$ for different soil layers in a column. The vertical displacements at points DV1 and DV2 are monitored to evaluate the soil settlement and monopile tilt. The acceleration and displacement at the tower top are also observed, denoted as AT and DT, respectively, to examine the dynamic responses of the OWT system. Fig. 8 shows the detailed layout of the monitoring points.

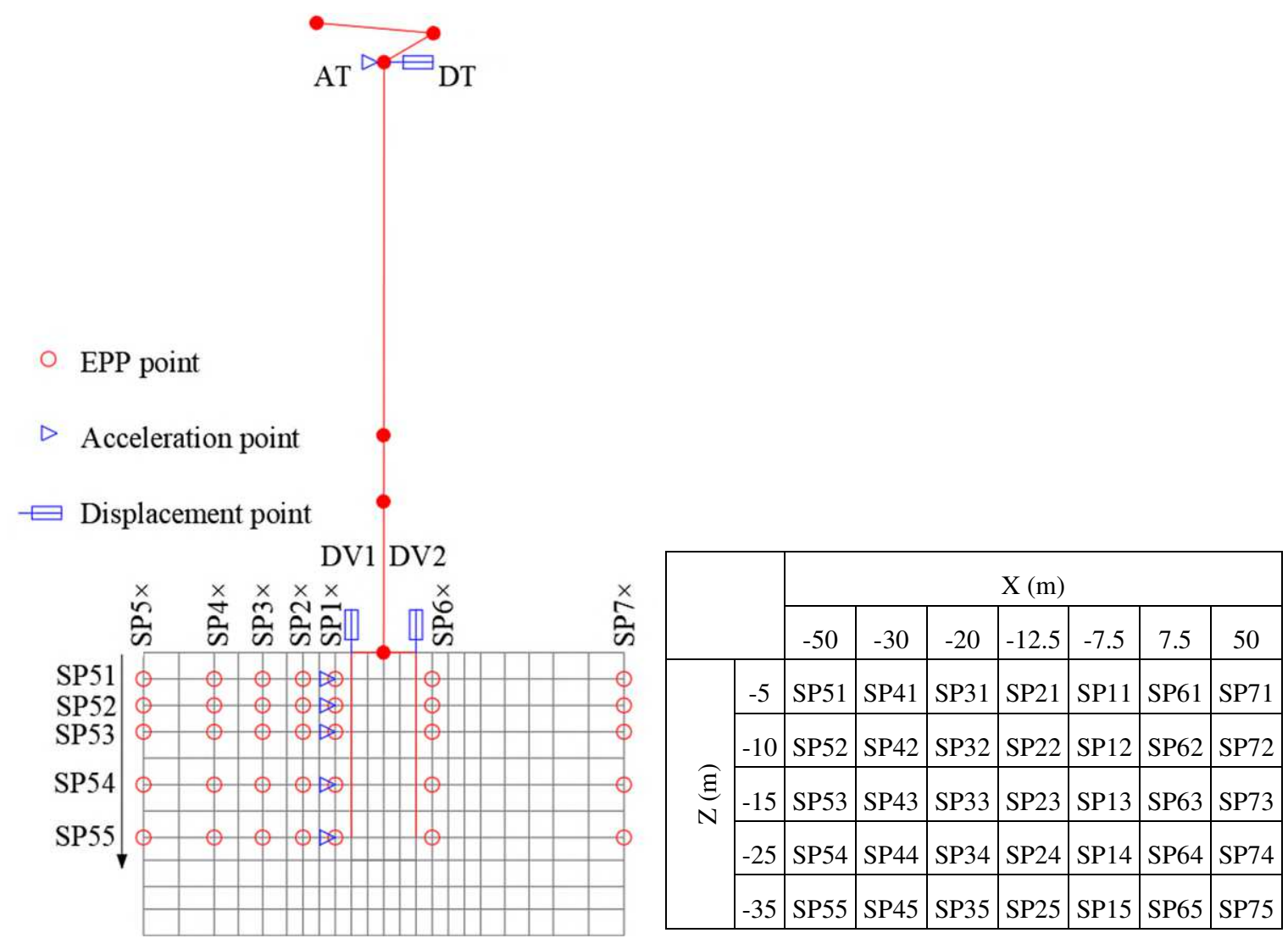

Fig. 8 Monitoring points in dynamic response and liquefaction analysis

Table 5 summarizes the major results obtained in the dynamic responses in three simulated loading scenarios. The tower top displacement is examined to guarantee stable levels and normal operations of the components (e.g., gearbox, generator, and other equipment) in the nacelle. The pile rotation angle at the mudline shows the inclination of the OWT in the service. The pile bending moment below the mudline is also examined because this index is sensitive to the loading variation transferred from the WT system and the liquefaction developed in the surrounding soil domain. Moreover, the moments 
409 could also be employed to evaluate the foundation bearing capacity. Finally, the EPP, which is defined 410 as the difference between the instantaneous pore water pressure and the hydrostatic pore pressure, at

411 the monitoring points SP11, SP12, and SP13 (on the left side of monopile) is presented to illustrate 412 the EPP accumulation and assess the liquefaction distribution.

413 As the dynamic response and liquefaction development under five selected earthquake records 414 follow a similar trend, the following subsections mainly focus on the Kobe earthquake to explain the 415 dynamic responses and liquefaction potential. This event causes the most severe liquefaction 416 distribution and capacity deterioration.

\section{Table 5}

418 Dynamic response and liquefaction distribution under different simulation scenarios

\begin{tabular}{|c|c|c|c|c|c|c|c|c|}
\hline \multirow{3}{*}{ Loading ca } & & \multirow{3}{*}{$\begin{array}{c}\text { Tower } \\
\text { Tower top } \\
\text { displacement } \\
\text { (m) }\end{array}$} & \multicolumn{2}{|c|}{ Pile } & \multicolumn{4}{|c|}{ Soil } \\
\hline & ses & & \multirow{2}{*}{$\begin{array}{l}\text { Rotation } \\
\text { at mudline } \\
\left(^{\circ}\right)\end{array}$} & \multirow{2}{*}{$\begin{array}{c}\text { Max bending } \\
\text { moment } \\
(\mathrm{MN}-\mathrm{m})\end{array}$} & \multirow{2}{*}{$\begin{array}{l}\text { Liquefied } \\
\text { depth }(m)\end{array}$} & \multicolumn{3}{|c|}{$\operatorname{Max} \operatorname{EPP}^{1}(\mathrm{kPa})$} \\
\hline & & & & & & $Z=-5 m$ & $Z=-10 m$ & $Z=-15 m$ \\
\hline \multirow{5}{*}{$\begin{array}{l}\text { Scenario } 1 \\
\quad(\mathrm{~S} 1)\end{array}$} & E1 & - & - & - & 5 & 44.7 & 52.5 & 47.6 \\
\hline & E2 & - & - & - & 5 & 44.4 & 54.2 & 57.3 \\
\hline & E3 & - & - & - & 10 & 44.8 & 88.3 & 87.2 \\
\hline & E4 & - & - & - & 5 & 44.5 & 57.1 & 51.1 \\
\hline & E5 & - & - & - & 0 & 33.5 & 22.6 & 16.4 \\
\hline \multirow{5}{*}{$\begin{array}{c}\text { Scenario } 2 \\
\text { (S2) }\end{array}$} & E1 & 0.114 & 0.065 & 418.3 & 10 & 64.1 & 90.5 & 105.7 \\
\hline & E2 & 0.105 & 0.097 & 492.3 & 10 & 60.0 & 90.5 & 123.8 \\
\hline & E3 & 0.221 & 0.145 & 724.6 & 15 & 59.2 & 102.0 & 141.6 \\
\hline & E4 & 0.309 & 0.092 & 430.9 & 10 & 59.3 & 91.2 & 120.5 \\
\hline & E5 & 0.017 & 0.035 & 279.9 & 5 & 52.8 & 52.4 & 38.2 \\
\hline \multirow{5}{*}{$\begin{array}{c}\text { Scenario } 3 \\
\text { (S3) }\end{array}$} & E1 & 1.135 & 0.126 & 808.9 & 10 & 67.6 & 96.0 & 102.0 \\
\hline & E2 & 1.167 & 0.158 & 777.6 & 10 & 68.5 & 93.1 & 117.4 \\
\hline & E3 & 1.317 & 0.210 & 1003.5 & 15 & 65.3 & 108.6 & 153.6 \\
\hline & E4 & 1.117 & 0.143 & 663.8 & 10 & 67.8 & 90.4 & 102.0 \\
\hline & E5 & 1.116 & 0.095 & 638.7 & 5 & 50.0 & 55.8 & 34.4 \\
\hline \multirow{5}{*}{$\begin{array}{c}\text { Scenario } 4 \\
\text { (S4) }\end{array}$} & E1 & 1.138 & 0.123 & 760.3 & 10 & 67.2 & 89.9 & 112.9 \\
\hline & E2 & 1.206 & 0.160 & 711.5 & 10 & 66.6 & 98.5 & 105.3 \\
\hline & E3 & 1.392 & 0.226 & 1052.8 & 15 & 46.9 & 107.4 & 149.6 \\
\hline & E4 & 1.142 & 0.130 & 716.8 & 10 & 72.6 & 91.5 & 97.6 \\
\hline & E5 & 1.142 & 0.087 & 627.3 & 5 & 50.5 & 60.0 & 32.5 \\
\hline
\end{tabular}

419 Note: 1 . The monitored soil points are located at $\mathrm{X}=-7.5 \mathrm{~m}$ and $\mathrm{Y}=0.0 \mathrm{~m}$. 


\subsection{The effect of seismic loading direction}

421 With the introduction of aerodynamic damping, the fore-aft and side-side damping ratios of the operating WT system are different. Therefore, two cases representing different induction directions of Kobe wave (E3) are considered in scenario 3 to clarify the influence of the angle between the wind and earthquake loadings and to select the severest liquefaction case in the following simulation. The detailed layouts of two cases are shown in Fig. 9. Considering the asymmetrical characteristics of loading when changing the earthquake incident directions, the full model, instead of the half model, is simulated.

(a)

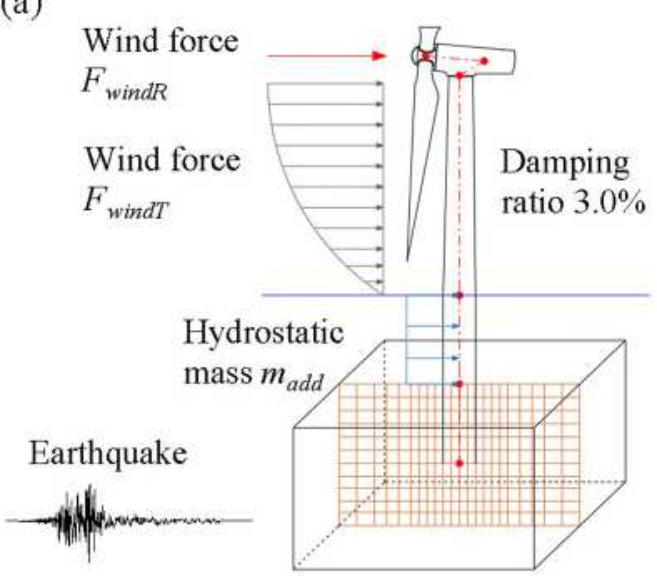

(b)

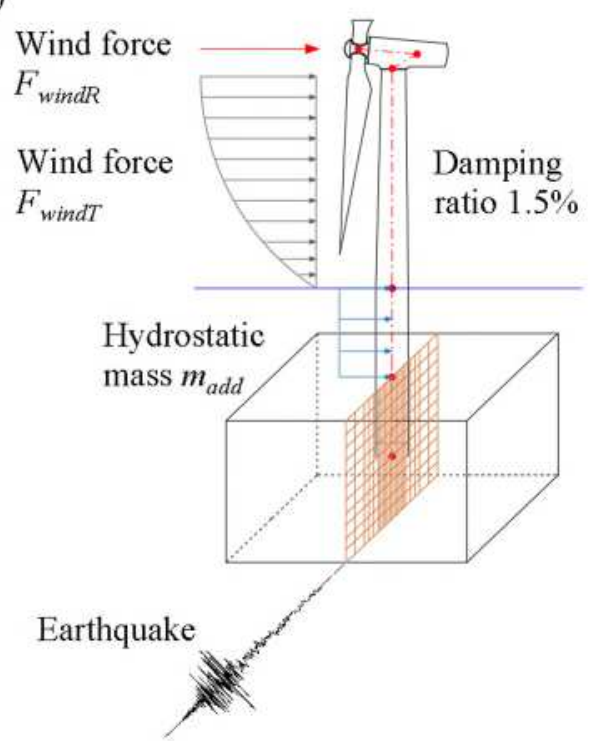

Fig. 9 OWT model considering different earhthquake induction directions in scenario 3 (a) case 1 and (b) case 2

The dynamic response and liquefaction severity are summarized in Table 6. In case 1, the tower top displacement, rotation angle, and maximum bending moment in the $\mathrm{Y}$ direction are nearly zero, as both the wind and earthquake loadings are applied in the $\mathrm{X}$ direction. In case 2, the dynamic responses in the $\mathrm{Y}$ direction intensify with the introduction of the earthquake in this direction. However, the maximum dynamic responses in Table 6 indicate that case 1 with the consistent wind and earthquake direction represents the severest situation. Therefore, the discussions in the following sub-sections are mainly focused on this most critical case. Comparing the results of the half model (shown in Table 5) and the full model - case 1 (shown in Table 6) verifies the accuracy of the half model when the wind and earthquake loading are applied in the same direction. 
441 Dynamic response and liquefaction distribution with and without considering aerodynamic damping

\begin{tabular}{|c|c|c|c|c|c|}
\hline \multirow{2}{*}{\multicolumn{2}{|c|}{ Loading cases }} & \multirow[b]{2}{*}{ Direction } & \multirow{2}{*}{$\begin{array}{c}\text { Tower } \\
\text { Tower top } \\
\text { displacement }(\mathrm{m})\end{array}$} & \multicolumn{2}{|c|}{ Pile } \\
\hline & & & & Rotation at & Max bending moment \\
\hline \multirow{4}{*}{$\begin{array}{c}\text { Scenario } 3 \\
\text { (S3) }\end{array}$} & \multirow{2}{*}{ Case $1^{1}$} & $\mathrm{X}$ & 1.302 & 0.209 & 1019.3 \\
\hline & & Y & 0.000 & 0.000 & 0.0 \\
\hline & \multirow{2}{*}{ Case $2^{2}$} & $\mathrm{X}$ & 1.206 & 0.112 & 525.4 \\
\hline & & $\mathrm{Y}$ & 0.236 & 0.098 & 798.2 \\
\hline
\end{tabular}

442

Note: 1. Wind and earthquake loading directions along the $\mathrm{X}$ axis; 2. Wind and earthquake loading directions along the $\mathrm{X}$ and $\mathrm{Y}$ axes, respectively.

\subsection{Liquefaction analysis of free-field soil (scenario 1)}

Fig. 10a presents the development of EPP under the Kobe earthquake in scenario 1. The EPP values increase dramatically during the first $15 \mathrm{~s}$ for all depths and then generally remain constant in the remaining time. The EPP of the shallow soil nodes accumulates quicker than those at deep layers because of the amplified soil responses observed at a shallow depth. In addition, the water depth-induced static water pressure imposed on the seabed prevents water drainage, which also contributes to the buildup of EPP at shallow layers. The EPP of the top layer (SP11 at $Z=-5 \mathrm{~m}$ ) reaches approximately $44.0 \mathrm{kPa}$, and the maximum EPP $(88.3 \mathrm{kPa})$ occurs at the depth of $Z=-10 \mathrm{~m}$ (SP12). The maximum EPP values at other monitoring nodes (SP13, SP14, and SP15) are 87.2, 78.3, and $68.9 \mathrm{kPa}$, respectively, which generally decreases with the increasing depth.
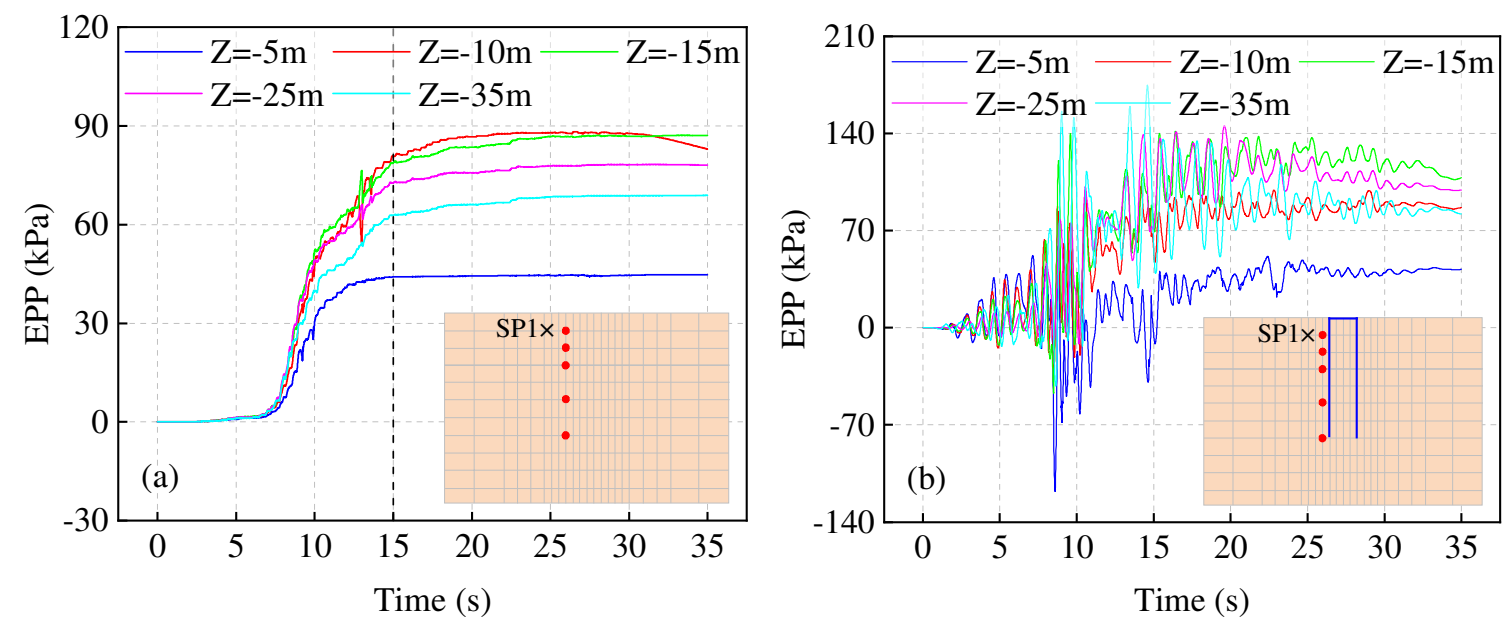

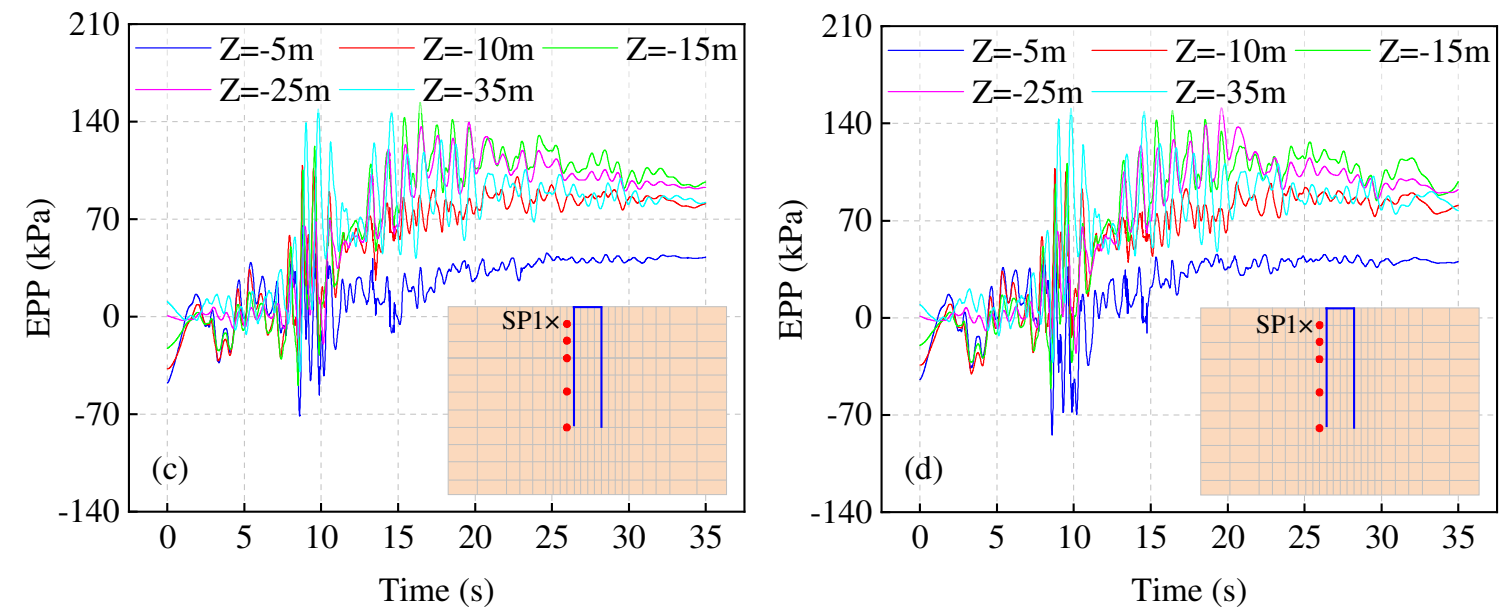

Fig. 10 EPP at different depths $Z$ under the Kobe earthquake: (a) free-field in scenario 1, (b) WT system in scenario 2, (c) WT system in scenario 3, and (d) WT system in scenario 4

The liquefaction areas could be judged by the excess pore water pressure ratio (EPPR) $r_{u}$,

$$
r_{u}=\frac{u(z)}{\sigma_{v 0}^{\prime}(z)}
$$

where $u(z)$ is the EPP at a depth of $z$ and $\sigma_{v 0}^{\prime}(z)$ is the initial vertical effective stress, which could be

460 determined based on the computation results before the input of ground motions. The liquefaction

461 takes place when the EPPR $r_{u}>0.9$. Fig. 11a shows the EPPR diagrams in scenario 1. The

462 liquefaction depth reaches approximately $10 \mathrm{~m}$ during the Kobe earthquake. The shallow layer

463 initially transforms into the liquefied state due to the lower effective stress and more significant

464 dynamic response. In addition, the EPPR (or EPP) of the soil nodes at the same horizontal level keeps

465 constant, satisfying the response characteristics of the free-field soil model.
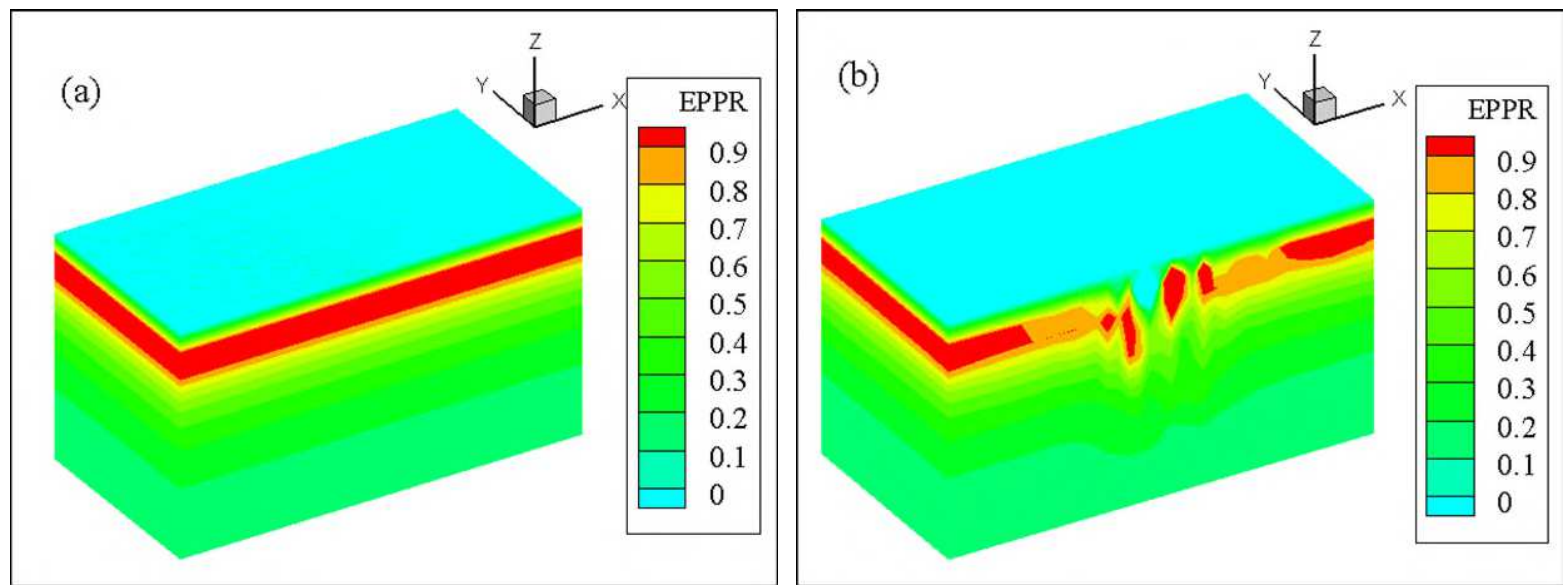


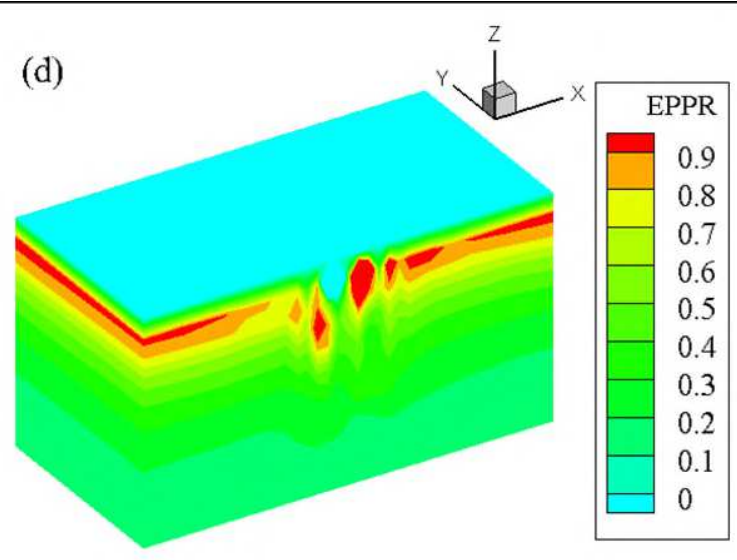

Fig. 11 Liquefaction distribution of the soil domain under the Kobe earthquake: (a) free-field in scenario 1, (b) WT system in scenario 2, (c) WT system in scenario 3, and (d) WT system in scenario 4

Table 5 presents the detailed results in scenario 1 (i.e., the free-field soil) under five earthquake records. The liquefaction does not occur under the Parkfield (E5) earthquake, but the liquefaction depths reach approximately $5 \mathrm{~m}$ under the other seismic ground motions except for the Kobe earthquake. Among four liquefied cases, the greatest EPP is observed under the Kobe (E3) earthquake, with the maximum EPP of $88.3 \mathrm{kPa}$ at the depth of $\mathrm{Z}=-10 \mathrm{~m}$. The different liquefaction severities under five ground motion records are attributed to the different intensities and frequency components of the selected earthquakes (Fig. 6). Compared with other seismic ground motions, the predominant frequency of the Kobe earthquake is closer to the fundamental frequency $(0.9 \mathrm{~Hz})$ of the free-field soil, which intensifies the dynamic responses and consequently leads to more severe liquefaction.

\subsection{OWT in the parked condition (scenario 2)}

The OWT system supported on a large-diameter monopile under earthquakes is simulated in scenario 2. Fig. 10b shows the EPP variation of the soil nodes SP1 $\times$ at different depths under the Kobe (i.e., E3) earthquake. The development history of EPP exhibits a similar trend as shown in the free field. However, the variation amplitude is more significant in scenario 2 due to the cyclic tension-compression stress induced by the monopile motion. In particular, the EPP around pile toe (i.e., the depth of $Z=-35 \mathrm{~m}$ ) in Fig. 10b accumulates more quickly than that in the free field, as shown in Fig. 10a. Furthermore, the maximum EPP values are approximately 68.9 and $174.7 \mathrm{kPa}$ in scenarios 1 and 2, respectively, which indicates greater stress transfer in this zone in scenario 2.

Fig. 11b shows the EPPR distribution under the Kobe earthquake in scenario 2 when the EPPR of SP13 $(Z=-15 \mathrm{~m})$ reaches the maximum value. At the selected instant, the soil inside and outside the 
pile shows different states. Considering the confinement of the pile wall, the EPPR of soil inside the monopile $(X=0 \mathrm{~m})$ is smaller than that outside $(X= \pm 7.5 \mathrm{~m})$, and correspondingly, more severe

492 liquefaction can be found outside of the monopile. Fig. 12a shows the EPP variation in the horizontal 493 direction at a selected depth of $\mathrm{Z}=-15 \mathrm{~m}$, which corresponds to the maximum liquefaction depth 494 (Table 5). The EPP variation is affected apparently by the monopile within the distance of $12.5 \mathrm{~m}$ 495 from the pile center, whereas the influence becomes limited beyond the distance of $20 \mathrm{~m}$ 496 (approximately twice the monopile diameter).
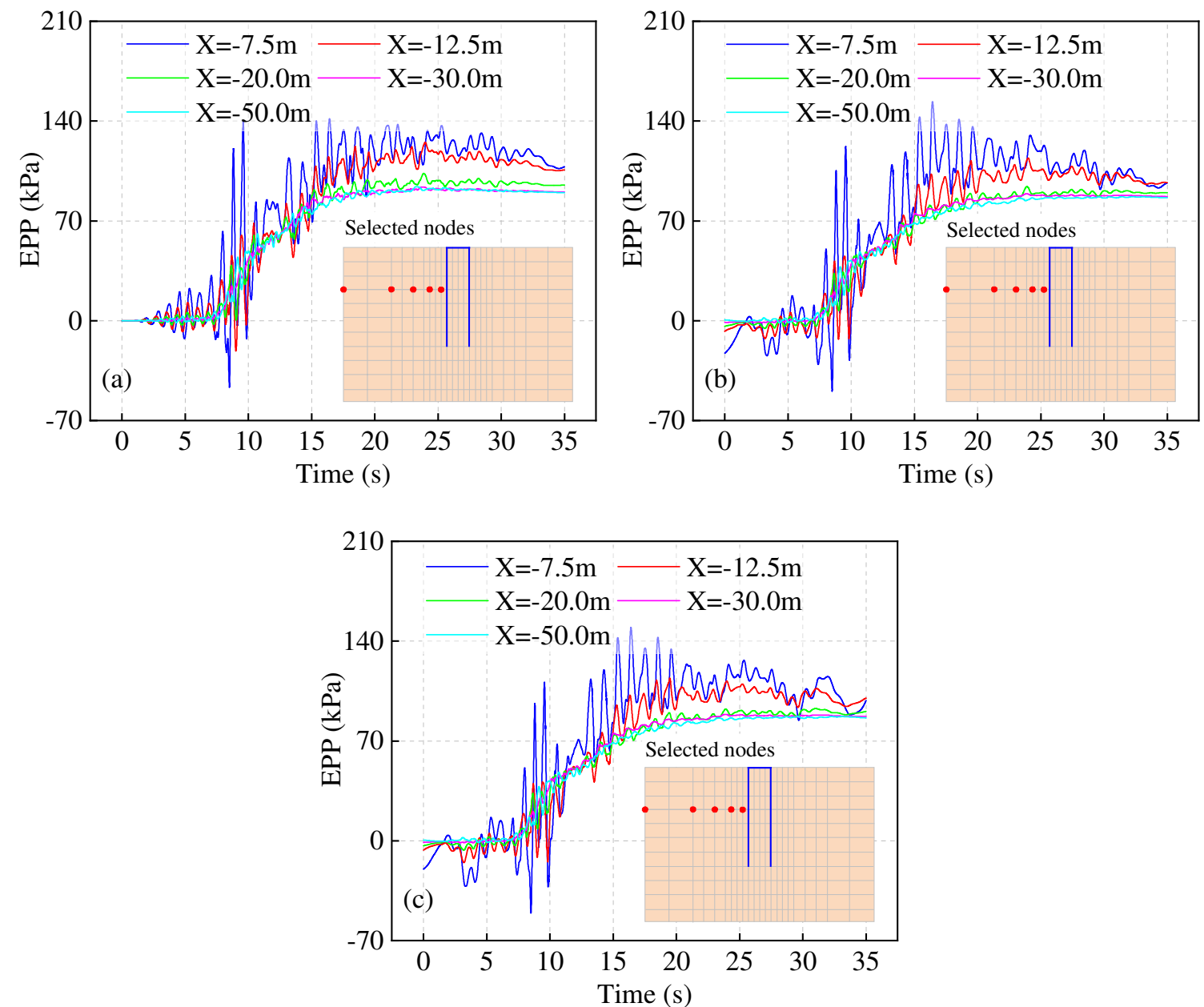

Fig. 12 EPP of soil nodes with different distances from the pile under Kobe earthquake: (a) EPP accumulation in scenario 2, (b) EPP accumulation in scenario 3, and (c) EPP accumulation in scenario 4

Fig. 13 shows the peak positive and negative bending moment distributions along the pile under the Kobe earthquake in scenario 2. The maximum bending moments are developed at the depth of approximately $10-15 \mathrm{~m}$, which is close to the interface of the liquefiable and non-liquefiable layers. This result is consistent with the observation made by Rahmani and Pak (2012) in traditioanl pile foundations. The averaged maximum and minimum bending moments during the Kobe earthquake are 

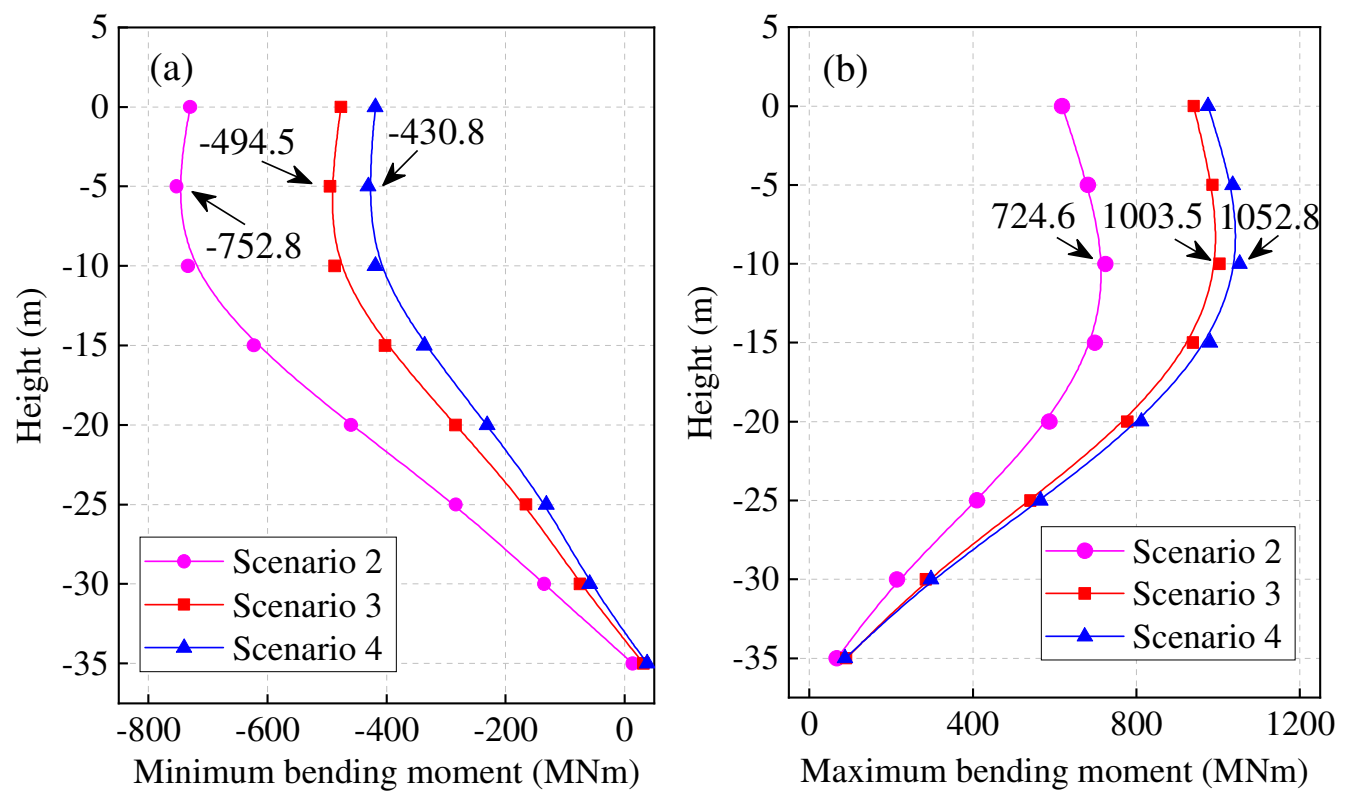

Fig. 13 Bending moment distribution along the monopile under the Kobe earthquake

In general, the introduction of the large-diameter monopile in scenario 2 intensifies the liquefaction severity under all five seismic records, as shown in Table 5. For example, the liquefaction occurs under the Parkfield earthquake in scenario 2 but not in the free field soil in scenario 1. Compared with the shallow soil layers $(Z=-5 \mathrm{~m})$, the EPP of soil at deeper positions $(Z=-10 \mathrm{~m})$ increases more significantly to reach the liquefied state under three seismic records (E2, E4, and E5). The most severe liquefied state is still observed in the Kobe case, in which the liquefaction depth expands to $15 \mathrm{~m}$.

Table 5 also presents the pile rotation and bending moment in scenario 2. The largest rotation angles and bending moments are observed under the Kobe earthquake, which is consistent with the liquefaction severity. Fig. 14 shows the time histories of the tower top displacement and the pile rotation at the mudline level under the Kobe earthquake. Given that the current IEC standard has not specified the detailed requirement for OWTs when considering the earthquake loading, some general specifications in different design codes are considered as the evaluation criteria, even though these limits are not intended for the seismic cases. FD 003-2007 (CREEI 2007) specifies a rotation angle limit of $0.17^{\circ}$ for WTs, whereas DNV-OS-J101 (DNV 2014) defines another limit of $0.25^{\circ}$ for OWT structures. These rotation angles are specified to meet the visual requirements and ensure the normal drivetrain operation. GB 50135-2019 (MoHURD 2019) defines an upper limit of tower top displacement as $1 / 75$ of the tower height for high-rise structures, including WT towers, to guarantee adequate resistance capacity. These threshold values are set to meet the requirements for the normal 
serviceability of WTs. Fig. 14 depicts the corresponding values. None of these thresholds exceed in scenario 2, despite the occurrence of soil liquefaction. The residual tower top displacement and residual pile rotation after the Kobe earthquake are equal to $-0.035 \mathrm{~m}$ and $-0.002^{\circ}$, respectively.

530
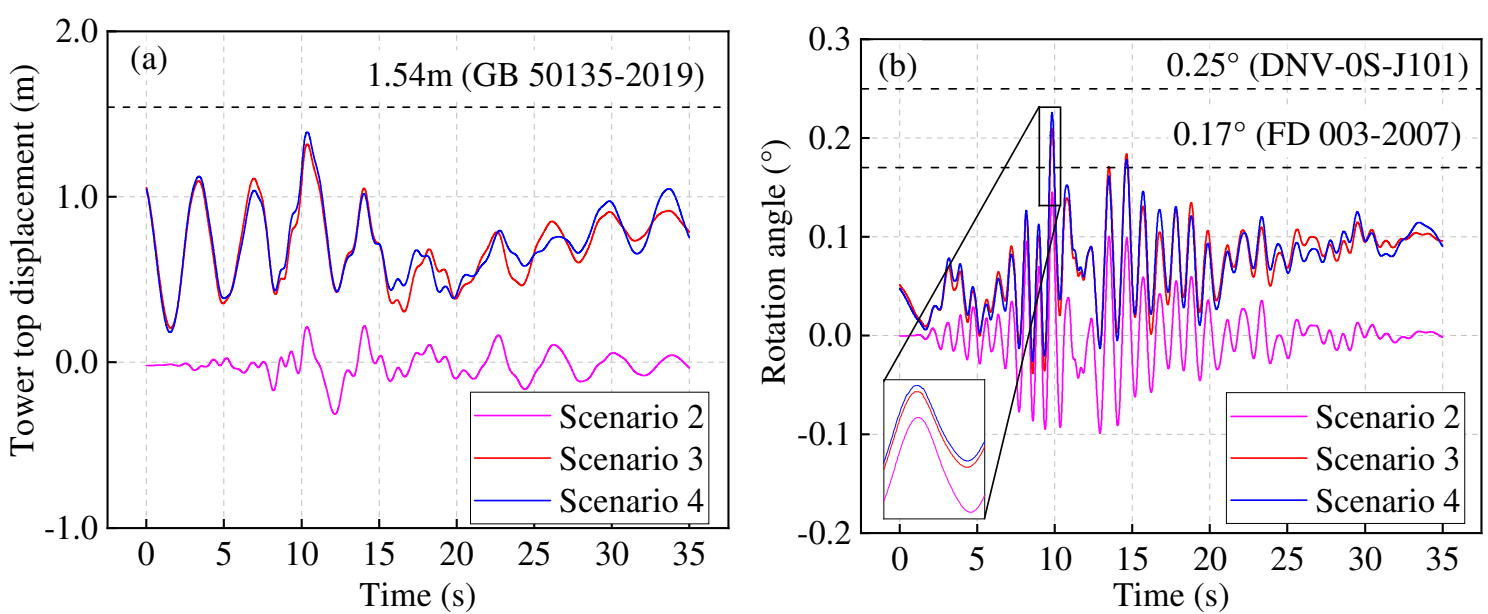

Fig. 14 Tower top displacement and pile rotation under the Kobe earthquake in scenarios 2-4: (a) tower top displacements and (b) pile rotation angles at the mudline

\subsection{OWT in the operating condition (scenarios 3 and 4)}

Scenarios 3 and 4 consider the OWT operating at a rated wind speed when an earthquake occurs with and without including wave loadings, respectively. As shown in Fig. 14a, the maximum displacement at the tower top in scenario 3 reaches $1.317 \mathrm{~m}$, which is 5.9 times the peak value in scenario 2 but is slightly smaller than the limit required in GB 50135-2019. The maximum value in scenario 4 is slightly larger, around $1.392 \mathrm{~m}$. It is noteworthy that turbulent wind loading has been applied before the earthquake attacks, and thus the initial displacement is not zero in two scenarios. Moreover, Fig. 14b shows that the time histories of the pile rotation angle under the Kobe earthquake in scenarios 3 and 4 have apparently different magnitudes from that of scenario 2 due to the addition of the wind loading. The maximum values under coupling loading are $0.210^{\circ}$ and $0.226^{\circ}$ respectively, which exceeds the $0.17^{\circ}$ limit defined in FD 003-2007 (CREEI 2007), but still satisfies the limit of $0.25^{\circ}$ in DNV-OS-J101 (DNV 2014).

Fig. 10c shows the EPP variation at the soil nodes next to the pile wall under the Kobe (E3) earthquake in scenario 3, wherein the EEP development history shows a trend similar to that in scenario 2. The time histories of EPP at different depths in scenario 4, as shown in Fig. 10d, are generally consistent with those in scenario 3, except for the normal soil node with a depth of $25 \mathrm{~m}$ where the corresponding EPP value is larger due to the introduction of wave loading. Fig. 15a directly 
compares the EPP development histories between scenarios 2 and 3 at a selected depth of $Z=-15 \mathrm{~m}$ corresponding to the maximum liquefaction depth in these two scenarios. A noticeable difference can

552 be observed between scenarios 2 and 3 for the soil nodes next to the pile wall $(\mathrm{X}=-7.5 \mathrm{~m})$.

553 Following the seismic record peak at $8.46 \mathrm{~s}$, the coupling effect of the wind and earthquake loading has a significant influence on EPP accumulation and leads to a larger value. In the remaining time, EPP values in scenario 2 are slightly greater. The effect of wave loading on the EPP accumulation is relatively limited when comparing the EPP values in scenarios 3 and 4, as shown in Fig. 15b. The EPPR distribution in scenarios 3 and 4 when the EPPR of SP13 $(\mathrm{Z}=-15 \mathrm{~m})$ reaches the maximum is shown in Fig. 11c and Fig. 11d, and similar liquefaction distributions could be found.
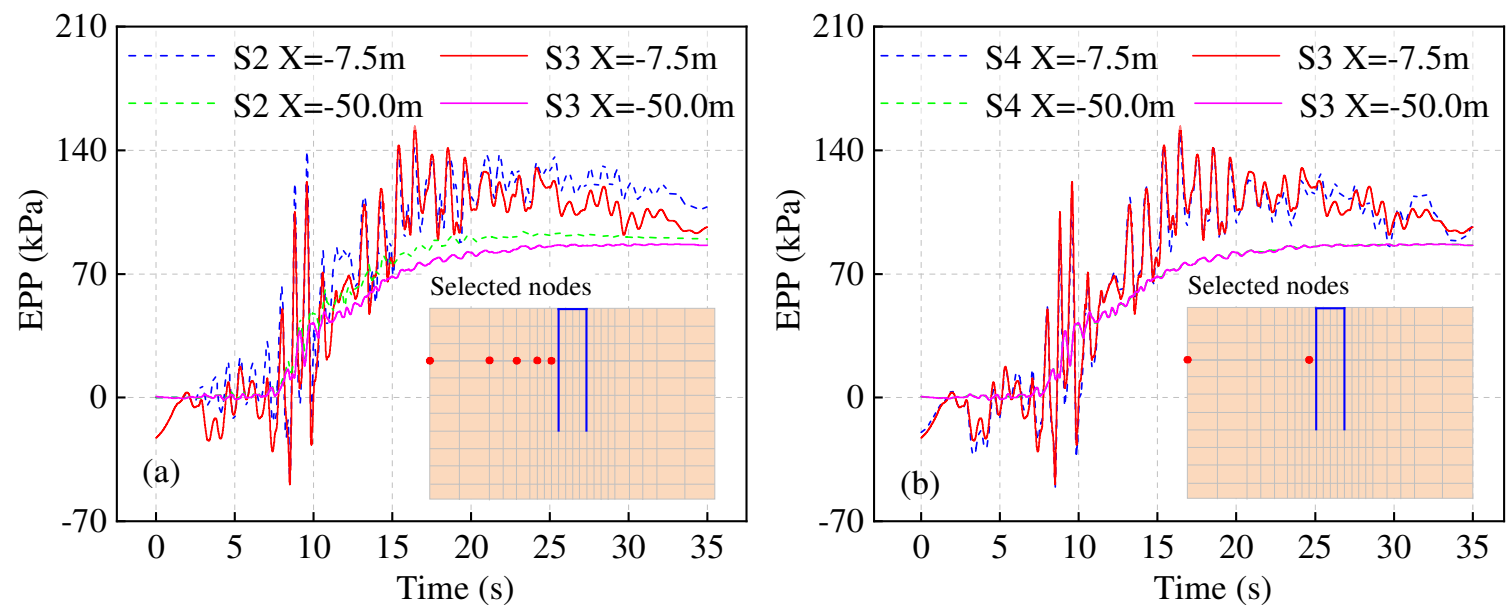

Fig. 15 EPP comparison of soil nodes with different distances from the pile under Kobe earthquake in (a) scenarios 2 and 3, and (d) scenarios 3 and 4

Fig. 13 shows the bending moment distributions along with the pile under the Kobe earthquake in scenarios 3 and 4 . The maximum positive bending moments are equal to 1003.5 and $1052.8 \mathrm{MN}-\mathrm{m}$, respectively, in scenarios 3 and 4; while the minimum values are -494.5 and $-430.8 \mathrm{MN}-\mathrm{m}$. The maximum bending moment increases slightly when including the wave loading. In comparison to scenario 2, although the maximum negative bending moment becomes smaller in scenarios 3 and 4 , the maximum positive bending moment, which is regarded as a dominant component, is significantly amplified under the coupled loadings.

Fig. 16 directly compares the peak values of several key indices among four scenarios, including the EPP of shallow soil nodes and the maximum bending moments and rotation angles of the monopile. As shown in Fig. 16a, the EPP values in the free-field soil are very close under five earthquakes except for the Kobe earthquake (E3), whereas the introduction of the OWT and monopile 
in scenario 2 will considerably increase the EPP values by $15.5 \%-132.1 \%$. The maximum increment ratio of $132.1 \%$ occurs in the Parkfield earthquake (E5) when the liquefaction phenomenon appears with the introduction of WT. The further addition of wind loading in scenario 3 only increases the EPP values slightly $(<7 \%)$ compared to that in scenario 2 . The influence of wave loading on the EPP variation in scenario 4 is not consistent. The EPP values slightly increase in Northbridge, Chi-Chi, and Parkfield earthquakes (E2, E4, and E5), while the smaller EPP could be found in the other two seismic records.

However, the effects of the coupled earthquake and wind loadings (scenario 3) become more evident in the pile rotation angles and bending moments, as shown in Fig. 16b and Fig. 16c, respectively. The increment ratios range from $38.5 \%$ to $128.2 \%$ under the coupled earthquake and wind loadings for the maximum bending moment, and the increment ratios of the pile rotation angle at the mudline range from $44.8 \%$ to $171.4 \%$. The liquefaction severity has a significant impact on the bending moments and rotation angles of the monopile. Given that the liquefaction depth is only $5 \mathrm{~m}$ under the Parkfield (E5) earthquake, the bending moment and rotation angle are relatively small. By contrast, with the largest liquefaction depth under the Kobe (E3) earthquake, bending moment and rotation angles are maxima among the five earthquake cases. The significant liquefaction weakens the stiffness and capacity of the soil foundation and thus amplifies the dynamic responses of the monopile and superstructure. When including the wave loading in scenario 4, the rotation angle and bending moment are not increased except for the Kobe earthquake, which corresponds to the severest liquefaction condition. The increment ratios of the rotation angle and maximum bending moment under the Kobe eaerthquake are $7.5 \%$ and $4.9 \%$, respectively.

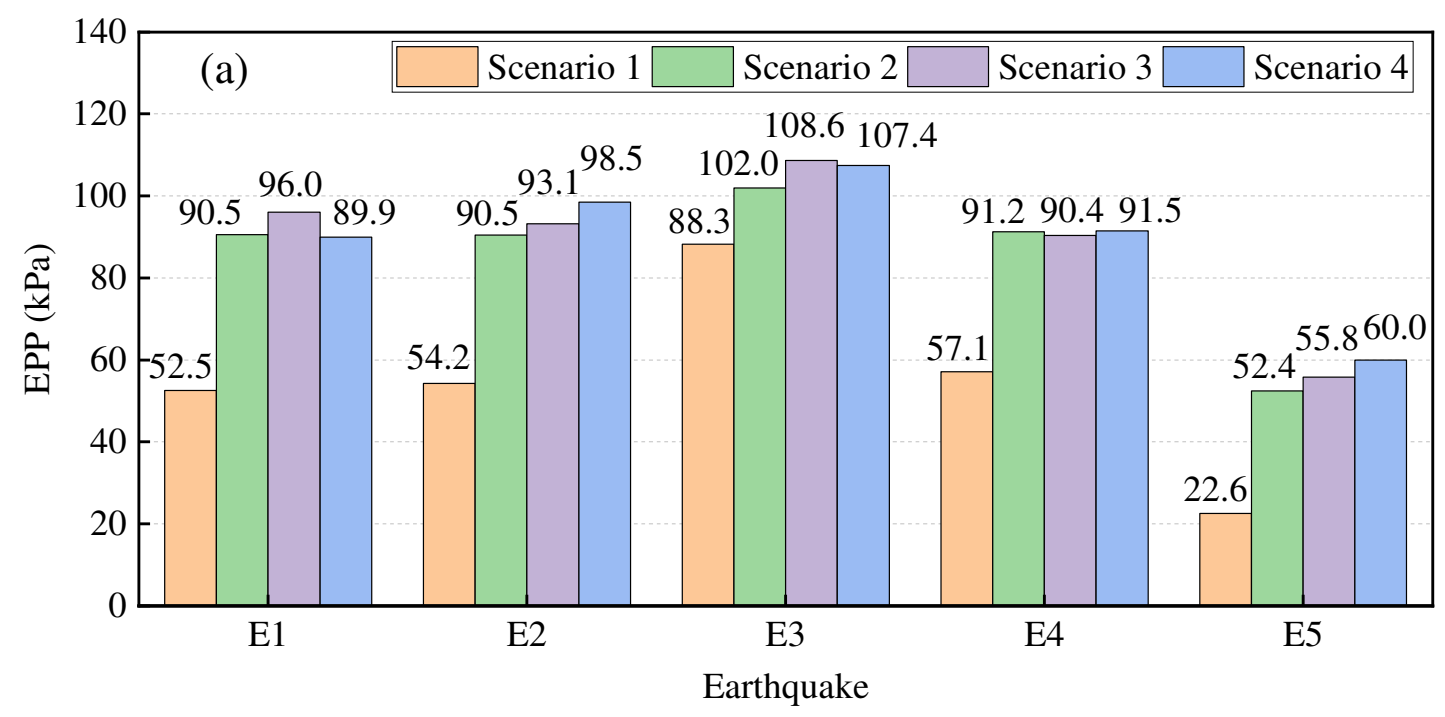




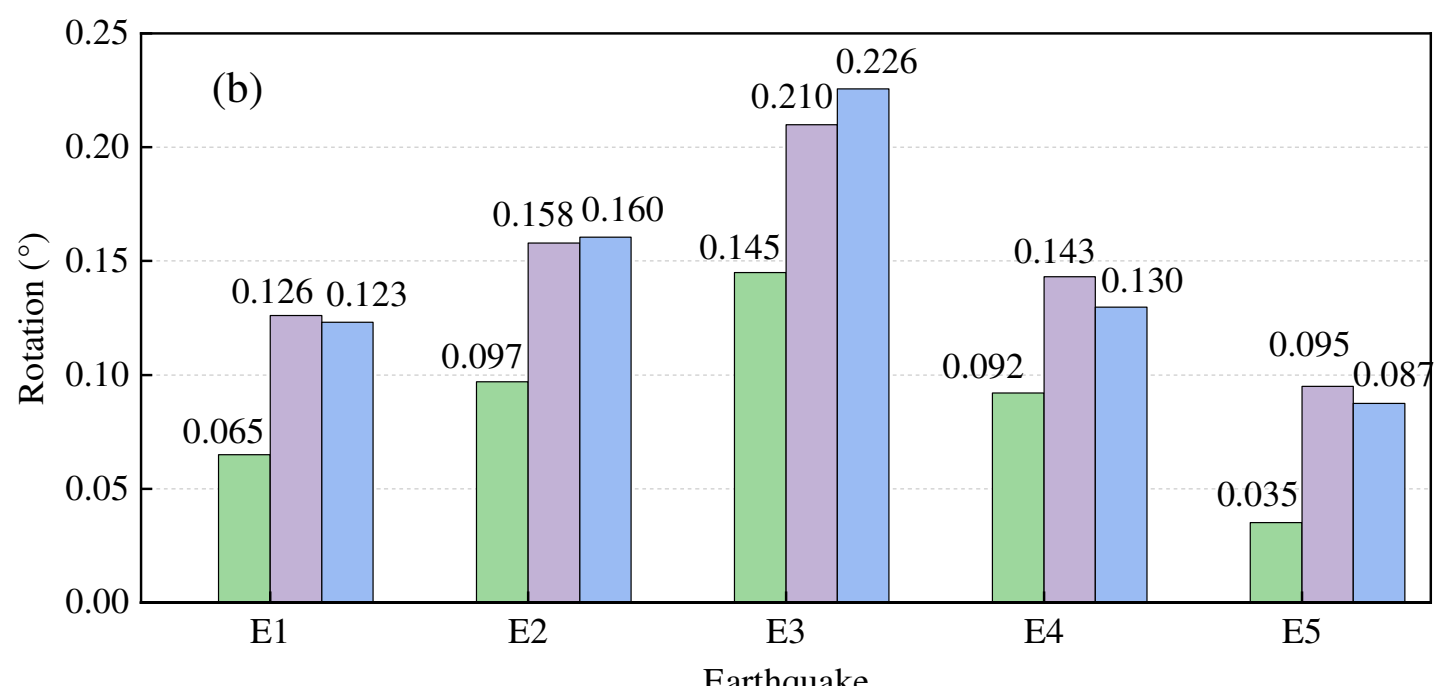

595

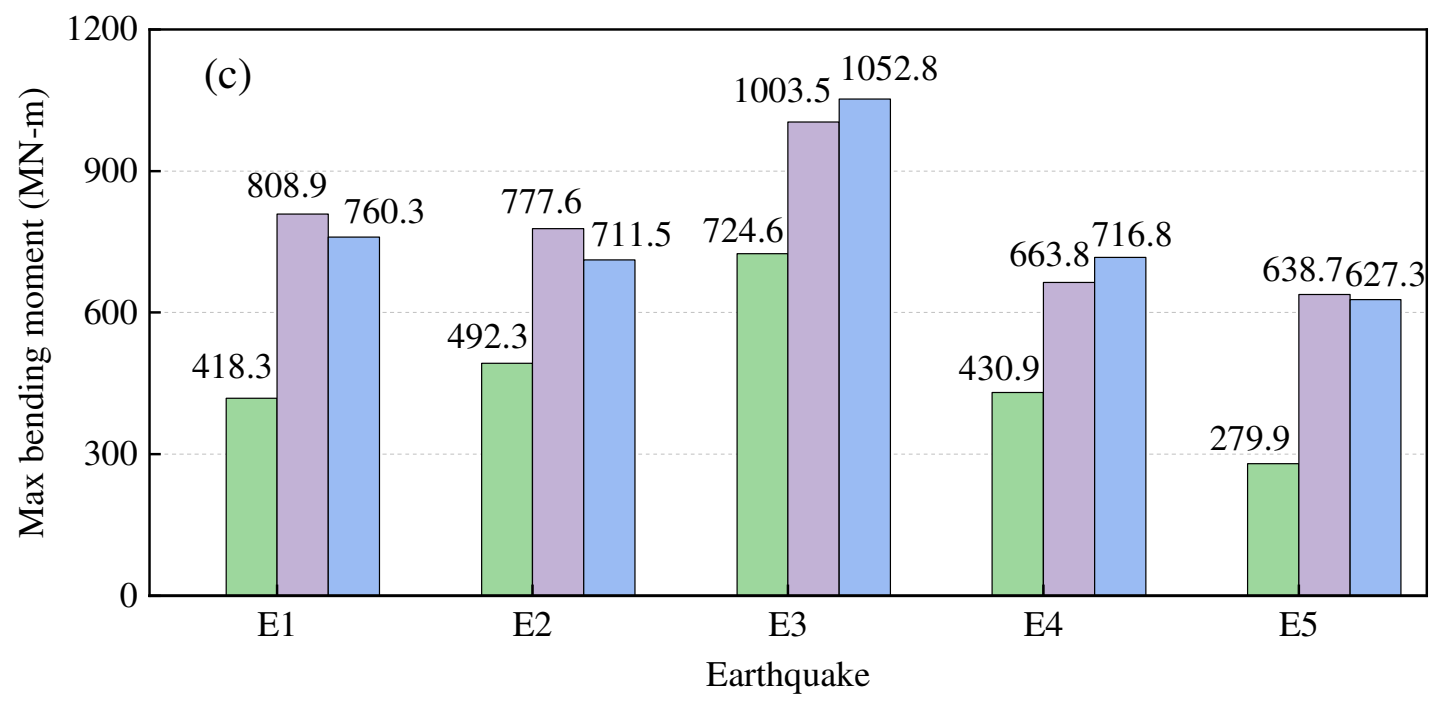

Fig. 16 Comparison of various performance indices among four scenarios: (a) EPP of soil node with a depth of $10 \mathrm{~m}$, (b) pile rotation angle at the mudline, and (c) maximum bending moment along the pile

Fig. 17 depicts the shear stress-shear strain and shear stress-mean effective stress relationships of soil nodes at two selected depths in scenarios 3. The soil node at a depth of $10 \mathrm{~m}$ experiences the maximum shear stress amplitude of $107.06 \mathrm{kPa}$ and the maximum shear strain of $1.906 \%$ in scenario 3, as shown in Fig. 17a. The corresponding values in scenario 2 are only $69.88 \mathrm{kPa}$ and $1.853 \%$, respectively, which are not shown in this study for brevity. The relatively larger shear stress amplitude and accumulated strain under the coupled loading intensify soil performance deterioration in scenario 3. Fig. 17b also indicates that the mean effective stress gradually reduces to zero with the loading cycles during the earthquake, indicating the liquefaction process. In comparison to $10-\mathrm{m}$ depth, although the soil node at $25 \mathrm{~m}$ depth in Fig. 17c experiences larger shear stress, the node is not finally liquefied given the positive mean effective stress. 
610 corresponding shear stress amplitude (104.44 kPa) and maximum shear strain $(1.904 \%)$ at shallow

611 depth $(\mathrm{Z}=-10 \mathrm{~m})$ are smaller than those in scenario 3. For the sake of brevity, the diagrams for 612 scenario 4 are not shown in Fig. 17.
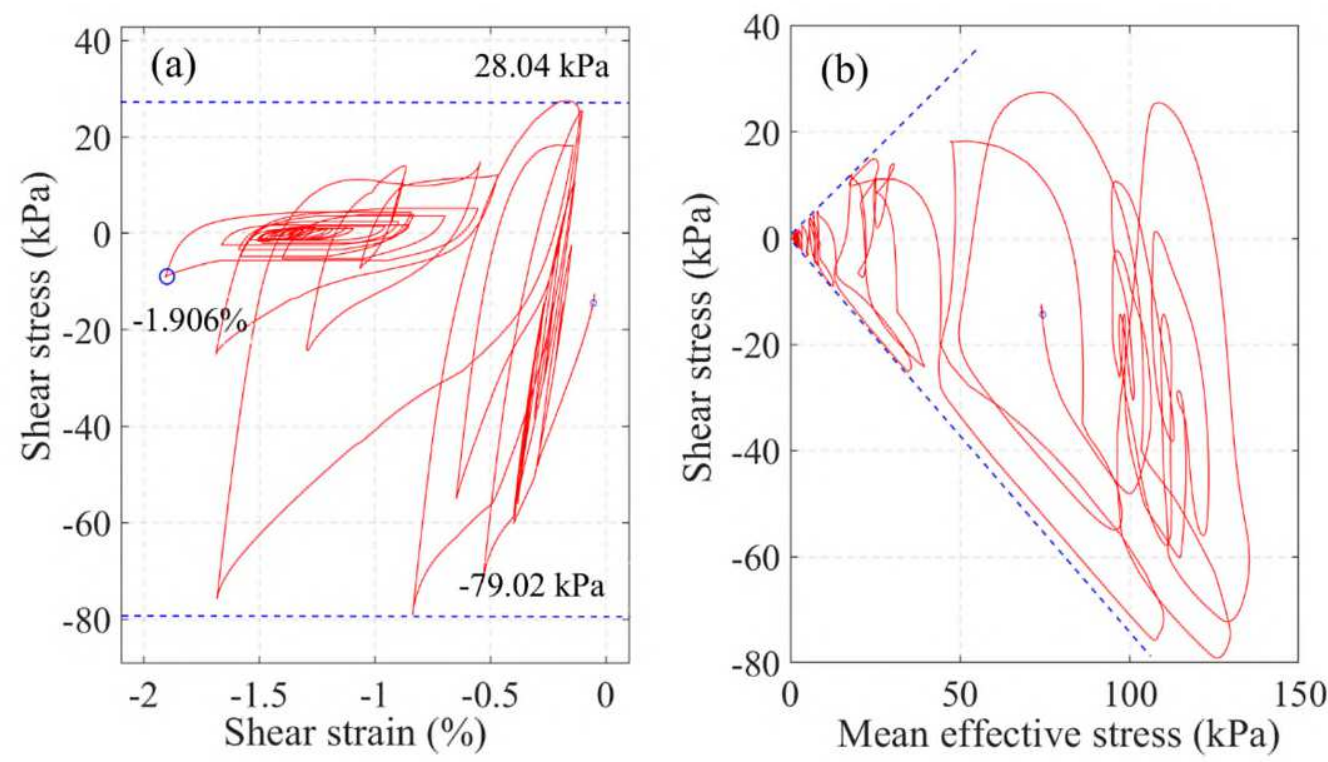

613
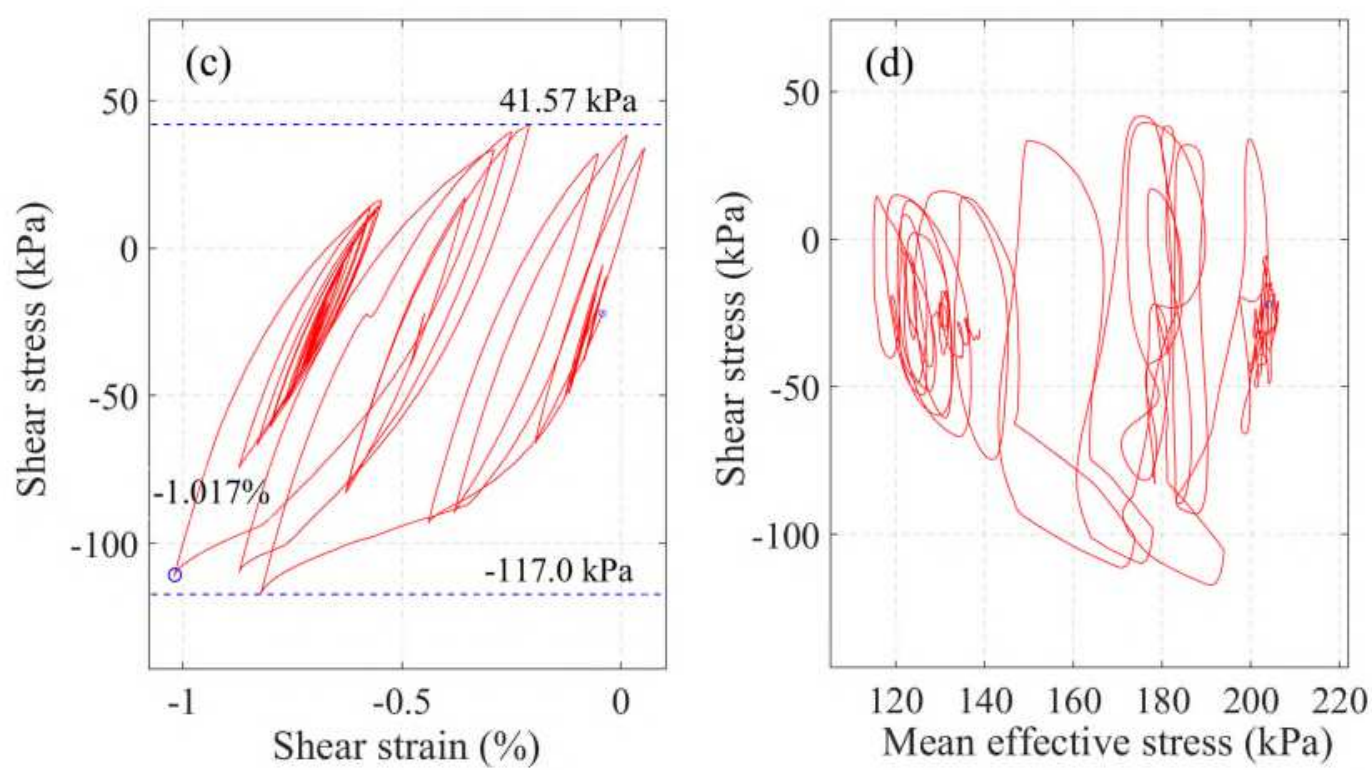

614

Fig. 17 Shear stress-strain and shear stress-mean effective stress relationships of soil nodes around the piles under Kobe earthquake in scenario 3: (a) shear stress-strain relationship at $Z=-10 \mathrm{~m}$, (b) shear stress-mean effective stress relationship at $Z=-10 \mathrm{~m}$, (c) shear stress-strain relationship at $\mathrm{Z}=-25 \mathrm{~m}$, and (d) shear stressmean effective stress relationship at $Z=-25 \mathrm{~m}$

\section{Conclusions}

Based on a three-dimensional FE model of a 10-MW OWT with a large-diameter monopile, the impact of earthquake-induced seabed liquefaction on a large-scale OWT is systematically assessed in 
the current study. The solid-fluid fully coupled element based on Biot's theory for porous medium and the pressure-dependent elastoplastic model is employed to assess soil displacement and pore water pressure. Five representative earthquake records are selected to evaluate the dynamic responses of the OWT under combined earthquake and wind loadings. The major findings are summarized as follows:

(1) Compared with free field soil, the large-diameter monopile considerably increases the EPP of the soil surrounding the pile, particularly at the pile toe. However, the influence of the pile becomes limited for soil with a horizontal plan distance beyond twice the pile diameter.

(2) The motions of the OWT under earthquake loadings increase the liquefaction depth and intensify the liquefaction severity.

(3) Compared with earthquake loadings, the coupled wind and earthquake loadings have small effects on the EPP values of soil. However, the introduction of wind loading leads to increased shear stress amplitude and accumulated shear strain, which has a critical influence on soil degradation.

(4) The liquefaction reduces the foundation stiffness and capacity of the OWT. Consequently, under the coupled wind and earthquake loadings, the pile rotation angles at the mudline and tower top displacements increase distinctly. In particular, the maximum pile rotation angle exceeds the limit specified in a Chinese standard.

(5) Considerably larger bending moment in the monopile is observed under the coupled wind and earthquake loadings. The peak bending moment occurs with the liquefaction, with the maximum value appearing close to the interface of the liquefiable and non-liquefiable soil layers.

(6) Compared with the wind loading, the influence of wave loading on the dynamic response (tower top displacement, pile rotation angle, and bending moment) and the liquefaction severity is limited.

(7) The strong coupling effect between the wind and earthquake loadings indicates that the past seismic analyses of OWTs that overlooked the liquefaction effect may have considerably underestimated the seismic risks of OWTs.

\section{Acknowledgments}

649 The authors are grateful for the financial supports provided by the Special Funds (Marine 650 Economic Development Use) for Promoting Economic Development in Guangdong Province, China 651 (Contract of Guangdong Natural Resources Department [2019]019), the NSFC/RGC Joint Research 

necessarily the views of the sponsors.

\section{CRediT Statement:}

Jian ZHANG: Methodology, Investigation, Validation, Visualization, Writing - original draft;

Guo-Kai YUAN: Funding acquisition, Project administration, Writing - review \& editing; Songye

ZHU: Conceptualization, Supervision, Funding acquisition, Writing - review \& editing; Quan GU:

Methodology, Validation; Shitang KE: Funding acquisition, Writing - review \& editing; Ai-Guo PEI:

Project administration, Writing - review \& editing

661

\section{References}

Alati N, Failla G, Arena F (2015) Seismic analysis of offshore wind turbines on bottom-fixed support structures Philos Trans A Math Phys Eng Sci 373:20140086. http://dx.doi.org/10.1098/rsta.2014.0086

Ali A, De Risi R, Sextos A, Goda K, Chang Z (2019) Seismic vulnerability of offshore wind turbines to pulse and non-pulse records Earthquake Eng Struct Dyn 49:24-50. https://doi.org/10.1002/eqe.3222

Arany L, Bhattacharya S, Macdonald J, Hogan SJ (2017) Design of monopiles for offshore wind turbines in 10 steps Soil Dyn Earthq Eng 92:126-152. http://dx.doi.org/10.1016/j.soildyn.2016.09.024

Asareh M, Schonberg W, Volz J (2016) Fragility analysis of a 5-MW NREL wind turbine considering aero-elastic and seismic interaction using finite element method Finite Elem Anal Des 120:57-67. http://dx.doi.org/10.1016/j.finel.2016.06.006

ASCE (2010) Minimum Design Loads for Buildings and Other Structures. American Society of Civil Engineers, Virginia, US

Bak C et al. (2013) Description of the DTU 10 MW Reference Wind Turbine. DTU Wind Energy, Roskilde, Denmark

Barari A, Bagheri M, Rouainia M, Ibsen LB (2017) Deformation mechanisms for offshore monopile foundations accounting for cyclic mobility effects Soil Dyn Earthq Eng 97:439-453. https://doi.org/10.1016/j.soildyn.2017.03.008

Bento N, Fontes M (2019) Emergence of floating offshore wind energy: Technology and industry Renew Sust Energy Rev 99:66-82. https://doi.org/10.1016/j.rser.2018.09.035

Cheng Z, Jeremić B (2009) Numerical modeling and simulation of pile in liquefiable soil Soil Dyn Earthq Eng 29:1405-1416. https://doi.org/10.1016/j.soildyn.2009.02.008

Chiaramonte MM, Arduino P, Lehman DE, Roeder CW (2013) Seismic analyses of conventional and improved marginal wharves Earthquake Eng Struct Dyn 42:1435-1450. https://doi.org/10.1002/eqe.2280

CREEI (2007) Design regulations on subgrade and foundations for wind turbine generator system vol FD 003-2007. China Water \& Power Press, Beijing, China (In Chinese) 
Dafalias YF, Manzari MT (2004) Simple Plasticity Sand Model Accounting for Fabric Change Effects J Eng Mech 130:622-634 https://doi.org/10.1061/(ASCE)0733-9399(2004)130:6(622)

Damgaard M, Zania V, Andersen LV, Ibsen LB (2014) Effects of soil-structure interaction on real time dynamic response of offshore wind turbines on monopiles Eng Struct 75:388-401. http://dx.doi.org/10.1016/j.engstruct.2014.06.006

De Risi R, Bhattacharya S, Goda K (2018) Seismic performance assessment of monopile-supported offshore wind turbines using unscaled natural earthquake records Soil Dyn Earthq Eng 109:154-172. https://doi.org/10.1016/j.soildyn.2018.03.015

DNV (2014) Design of Offshore Wind Turbine Structures vol DNV-OS-J101. Det Norske Veritas, Oslo, Denmark

DNVGL (2017) Environmental conditions and environmental loads. Det Norske Veritas and Germanischer Lloyd, Oslo, Norway

DNVGL (2019) Offshore soil mechanics and geotechnical engineering vol DNVGL-RP-C212. Det Norske Veritas and Germanischer Lloyd, Oslo, Norway

Dong RG (1978) Effective mass and damping of submerged structures. Lawrence Livermore National Laboratory, California, US

Elgamal A, Yan L, Yang Z, Conte JP (2008) Three-Dimensional Seismic Response of Humboldt Bay Bridge-Foundation-Ground System J Struct Eng 134:1165-1176. https://doi.org/10.1061/(ASCE)0733-9445(2008)134:7(1165)

Elgamala A, Yang Z, Parrab E (2002) Computational modeling of cyclic mobility and post-liquefaction site response Soil Dyn Earthq Eng 22:259-271. https://doi.org/10.1016/S0267-7261(02)00022-2

Esfeh PK, Kaynia AM (2019) Numerical modeling of liquefaction and its impact on anchor piles for floating offshore structures Soil Dyn Earthq Eng 127:105839. https://doi.org/10.1016/j.soildyn.2019.105839

Fan J, Li Q, Zhang Y (2019) Collapse analysis of wind turbine tower under the coupled effects of wind and near-field earthquake Wind Energy 22:407-419. https://doi.org/10.1002/we.2294

Frohboese P, Schmuck C, Hassan GG (2010) Thrust coefficients used for estimation of wake effects for fatigue load calculation. Paper presented at the In: European Wind Energy Conference and Exhibition 2010, Warsaw, Poland,

GWEC (2020) Global wind energy report 2019. Global Wind Energy Council, Brussels

Huang S, Huang M, Lyu Y, Xiu L (2021) Effect of sea ice on seismic collapse-resistance performance of wind turbine tower based on a simplified calculation model Eng Struct 227:111426. https://doi.org/10.1016/j.engstruct.2020.111426

Hudson M, Idriss IM, Beikae M (1994) User's Manual's for QUAD4M a computer program to evaluate the seismic response of soil structures using finite element procedures and incorporating a compliant base. University of California Davis, California

IEC (2019) Wind energy generation systems Part 3-1: Design requirements for fixed offshore wind turbines vol IEC 61400-3-1. International Electrotechnical Commission, Geneva, Switzerland

Igwemezie V, Mehmanparast A, Kolios A (2019) Current trend in offshore wind energy sector and material requirements for fatigue resistance improvement in large wind turbine support structures - A review Renew Sust Energy Rev 101:181-196. https://doi.org/10.1016/j.rser.2018.11.002 
ISO (2016) Petroleum and natural gas industries-Specific requirements for offshore structures Part 4: Geotechnical and foundation design considerations vol ISO 19901-4. International Organization for Standardization, Geneva, Switzerland

Jonkman BJ, M.L. Buhl J (2006) TurbSim User's Guide. National Renewable Energy Laboratory (NREL), Colorado, US

Jonkman JM, Jr. MLB (2005) FAST User's Guide. National Renewable Energy Laboratory (NREL), Colorado,US

Katsanos EI, Thöns S, Georgakis CT (2016) Wind turbines and seismic hazard: a state-of-the-art review Wind Energy 19:2113-2133. https://doi.org/10.1002/we.1968

Kaynia AM (2019) Seismic considerations in design of offshore wind turbines Soil Dyn Earthq Eng 124:399-407. https://doi.org/10.1016/j.soildyn.2018.04.038

Kementzetzidis E, Corciulo S, Versteijlen WG, Pisanò F (2019) Geotechnical aspects of offshore wind turbine dynamics from 3D non-linear soil-structure simulations Soil Dyn Earthq Eng 120:181-199. https://doi.org/10.1016/j.soildyn.2019.01.037

Kim DH, Lee SG, Lee IK (2014) Seismic fragility analysis of 5 MW offshore wind turbine Renew Energy 65:250-256. http://dx.doi.org/10.1016/j.renene.2013.09.023

Kjørlaug RA, Kaynia AM (2015) Vertical earthquake response of megawatt-sized wind turbine with soil-structure interaction effects Earthquake Eng Struct Dyn 44:2341-2358. https://doi.org/10.1002/eqe.2590

Kuo Y, Chong K, Tseng Y, Hsu C, Lin C (2020) Assessment on liquefaction potential of seabed soil in Chang-Bin Offshore wind farm considering parametric uncertainty of standard penetration tests Eng Geol 267:105497. https://doi.org/10.1016/j.enggeo.2020.105497

Law HK, Lam IP (2001) Application of Periodic Boundary for Large Pile Group J Geotech Geoenviron Eng 127:889-892. https://doi.org/10.1061/(ASCE)1090-0241(2001)127:10(889)

Li X, Chen S, Ren Z, Lv Y, Tong H, Wen Z (2020) Project plan and research progress on key technologies of seismic zoning in sea areas Progress in Earthquake Sciences 50:2-19. (In Chinese)

Li X, Zeng X, Yu X, Wang X (2021) Seismic response of a novel hybrid foundation for offshore wind turbine by geotechnical centrifuge modeling Renew Energy:1404-1416. https://doi.org/10.1016/j.renene.2020.11.140

Lu J, Elgamal A, Yan L, Law KH, Conte JP (2011) Large-Scale Numerical Modeling in Geotechnical Earthquake Engineering Int J Geomech 11:490-503. https://doi.org/10.1061/(ASCE)GM.1943-5622.0000042

Manzari MT, Dafalias YF (1997) A critical state two-surface plasticity model for sands Géotechnique 47:255-272. https://doi.org/10.1680/geot.1997.47.2.255

Martín del Campo JO, Pozos-Estrada A (2020) Multi-hazard fragility analysis for a wind turbine support structure: An application to the Southwest of Mexico Eng Struct 209:109929. https://doi.org/10.1016/j.engstruct.2019.109929

Mo R, Kang H, Li M, Zhao X (2017) Seismic Fragility Analysis of Monopile Offshore Wind Turbines under Different Operational Conditions Energies 10:1037. https://doi.org/10.3390/en10071037

MoHURD (2016) Code for seismic design of buildings vol GB 50011-2010. China Planning Press, Beijing, China (In Chinese) 
MoHURD (2019) Standard for design of high-rising structures. China Planning Press, Beijing, China (In Chinese)

Moriarty PJ, Hansen AC (2005) AeroDyn Theory Manual. National Renewable Energy Laboratory (NREL), Colorado, US

Negro V, LópezGutiérrez J, Esteban MD, Matutano C (2014) Uncertainties in the design of support structures and foundations for offshore wind turbines Renew Energy 63:125-132. http://dx.doi.org/10.1016/j.renene.2013.08.041

OffshoreWIND (2019) GE Haliade-X 12MW Produces First Power in Rotterdam. https://www.offshorewind.biz/2019/11/07/ge-haliade-x-12mw-produces-first-power-in-rotter $\underline{\text { dam } / .}$

Oh K, Nam W, Ryu MS, Kim J, Epureanu BI (2018) A review of foundations of offshore wind energy convertors: Current status and future perspectives Renew Sust Energy Rev 88:16-36. https://doi.org/10.1016/j.rser.2018.02.005

Patil A, Jung S, Kwon O-S (2016) Structural performance of a parked wind turbine tower subjected to strong ground motions Eng Struct 120:92-102. http://dx.doi.org/10.1016/j.engstruct.2016.04.020

Patra SK, Haldar S (2018) Response of monopile supported offshore wind turbine in liquefied soil. Paper presented at the In: Indian Geotechnical Conference, Bengaluru, India,

Prevost JH (1977) Mathematical modelling of monotonic and cyclic undraind clay behavior Int J Numer Anal Methods Geomech 1:195-216. https://doi.org/10.1002/nag.1610010206

Prevost JH (1985) A simple plasticity theory for frictional cohesionless soils Soil Dyn Earthq Eng 4:9-17. https://doi.org/10.1016/0261-7277(85)90030-0

Prowell I, Veers P (2009) Assessment of Wind Turbine Seismic Risk: Existing Literature and Simple Study of Tower Moment Demand. Sandia National Laboratories, Albuquerque, New Mexico 87185 and Livermore, California 94550, USA

Qiu Z, Lu J, Elgamal A, Su L, Wang N, Almutairi A (2019) OpenSees Three-Dimensional Computational Modeling of Ground-Structure Systems and Liquefaction Scenarios Comput Model Eng Sci 120:629-656. https://doi.org/10.32604/cmes.2019.05759

Quilligan A, O’Connor A, Pakrashi V (2012) Fragility analysis of steel and concrete wind turbine towers Eng Struct 36:270-282. https://doi.org/10.1016/j.engstruct.2011.12.013

Rahmani A, Pak A (2012) Dynamic behavior of pile foundations under cyclic loading in liquefiable soils Comput Geotech 40:114-126. https://doi.org/10.1016/j.compgeo.2011.09.002

Santangelo F, Failla G, Arena F, Ruzzo C (2018) On time-domain uncoupled analyses for offshore wind turbines under seismic loads Bull Earthquake Eng 16:1007-1040. https://doi.org/10.1007/s10518-017-0191-x

Santangelo F, Failla G, Santini A, Arena F (2016) Time-domain uncoupled analyses for seismic assessment of land-based wind turbines Eng Struct 123:275-299. http://dx.doi.org/10.1016/j.engstruct.2016.05.043

Seed HB, Idriss IM (1970) A Simplified Procedure for Evaluating Soil Liquefaction Potential. University of California Berkeley, California, US

Shanon and Wilson I (1976) Evaluation of Soil Liquefaction Potential for Level Ground during Earthquakes. Shannon \& Wilson, Inc. and Agbabian Associates, Seattle, Washington and El Segundo, California, US 
Sigurðsson GÖ, Rupakhety R, Rahimi SE, Olafsson S (2020) Effect of pulse-like near-fault ground motions on utility-scale land-based wind turbines Bull Earthquake Eng 18:953-968. https://doi.org/10.1007/s10518-019-00743-9

Sumer BM et al. (2007) Earthquake-Induced Liquefaction around Marine Structures J Waterw Port, Coast Ocean Eng 133:55-82. https://doi.org/10.1061/(ASCE)0733-950X(2007)133:1(55)

Valamanesh V, Myers AT (2014) Aerodynamic Damping and Seismic Response of Horizontal Axis Wind Turbine Towers J Struct Eng 140:04014090. https://doi.org/10.1061/(ASCE)ST.1943-541X.0001018

Veers P et al. (2019) Grand challenges in the science of wind energy Science 366:443. https://doi.org/10.1126/science.aau2027

Velarde J (2016) Design of Monopile Foundations to Support the DTU 10 MW Offshore Wind Turbine. Dissertation, Delft University of Science and Technology and Norwegian University of Science and Technology

Wan Y, Fan C, Dai Y, Li L, Sun W, Zhou P, Qu X (2018) Assessment of the Joint Development Potential of Wave and Wind Energy in the South China Sea Energies 11:398. https://doi.org/10.3390/en11020398

Wang P, Xu Y, Zhang X, Xi R, Du X (2021) A substructure method for seismic responses of offshore wind turbine considering nonlinear pile-soil dynamic interaction Soil Dyn Earthq Eng 144:106684. https://doi.org/10.1016/j.soildyn.2021.106684

Wang P, Zhao M, Du X, Liu J, Xu C (2018a) Wind, wave and earthquake responses of offshore wind turbine on monopile foundation in clay Soil Dyn Earthq Eng 113:47-57. https://doi.org/10.1016/j.soildyn.2018.04.028

Wang R, Fu P, Zhang J-M (2016a) Finite element model for piles in liquefiable ground Comput Geotech 72:1-14. https://doi.org/10.1016/j.compgeo.2015.10.009

Wang R, Zhang J-M, Wang G (2014) A unified plasticity model for large post-liquefaction shear deformation of sand Comput Geotech 59:54-66. https://doi.org/10.1016/j.compgeo.2014.02.008

Wang X, Yang X, Zeng X (2017) Seismic centrifuge modelling of suction bucket foundation for offshore wind turbine Renew Energy 114:1013-1022. http://dx.doi.org/10.1016/j.renene.2017.07.103

Wang X, Zeng X, Li J, Yang X, Wang H (2018b) A review on recent advancements of substructures for offshore wind turbines Energy Convers Manag 158:103-119. https://doi.org/10.1016/j.enconman.2017.12.061

Wang X, Zeng X, Li X, Li J (2020) Liquefaction characteristics of offshore wind turbine with hybrid monopile foundation via centrifuge modelling Renew Energy 145:2358-2372. https://doi.org/10.1016/j.renene.2019.07.106

Wang Y, Chai J, Chang Y, Huang T, Kuo Y (2016b) Development of Seismic Demand for Chang-Bin Offshore Wind Farm in Taiwan Strait Energies 9:1036. https://doi.org/10.3390/en9121036

Watson S et al. (2019) Future emerging technologies in the wind power sector: A European perspective Renew Sust Energy Rev 113:109270. https://doi.org/10.1016/j.rser.2019.109270

Wilson DW (1998) Soil-pile-superstructure Interaction in Liquefying Sand and Soft Clay. Dissertation, University of California, Davis

Wu X et al. (2019) Foundations of offshore wind turbines: A review Renew Sust Energy Rev 104:379-393. https://doi.org/10.1016/j.rser.2019.01.012 
Xiang N, Goto Y, Obata M, Alam MS (2019) Passive seismic unseating prevention strategies implemented in highway bridges: A state-of-the-art review Eng Struct 194:77-93. https://doi.org/10.1016/j.engstruct.2019.05.051

Yang Y, Bashir M, Li C, Wang J (2019a) Analysis of seismic behaviour of an offshore wind turbine with a flexible foundation Ocean Eng 178:215-228. https://doi.org/10.1016/j.oceaneng.2019.02.077

Yang Y, Li C, Bashir M, Wang J, Yang C (2019b) Investigation on the sensitivity of flexible foundation models of an offshore wind turbine under earthquake loadings Eng Struct 183:756-769. https://doi.org/10.1016/j.engstruct.2019.01.050

Yang Y, Ye K, Li C, Michailides C, Zhang W (2018) Dynamic behavior of wind turbines influenced by aerodynamic damping and earthquake intensity Wind Energy 21:303-319. https://doi.org/10.1002/we.2163

Yang Z, Lu J, Elgamal A (2008) OpenSees soil models and solid-fluid fully coupled elements User's Manual. University of California San Diego, California, US

Zafeirakos A, Gerolymos N (2013) On the seismic response of under-designed caisson foundations Bull Earthquake Eng 11:1337-1372. https://doi.org/10.1007/s10518-013-9465-0

Zhang P, Ding H, Le C (2014a) Seismic response of large-scale prestressed concrete bucket foundation for offshore wind turbines J Renew Sustain Energy 6:013127. http://dx.doi.org/10.1063/1.4863986

Zhang P, Xiong K, Ding H, Le C (2014b) Anti-liquefaction characteristics of composite bucket foundations for offshore wind turbines J Renew Sustain Energy 6:053102. https://doi.org/10.1063/1.4895909

Zhang X, Tang L, Ling X, Chan AHC, Lu J (2018) Using peak ground velocity to characterize the response of soil-pile system in liquefying ground Eng Geol 240:62-73. https://doi.org/10.1016/j.enggeo.2018.04.011

Zuo H, Bi K, Hao H (2018) Dynamic analyses of operating offshore wind turbines including soil-structure interaction Eng Struct 157:42-62. https://doi.org/10.1016/j.engstruct.2017.12.001

Zuo H, Bi K, Hao H, Li C (2019) Influence of earthquake ground motion modelling on the dynamic responses of offshore wind turbines Soil Dyn Earthq Eng 121:151-167. https://doi.org/10.1016/j.soildyn.2019.03.008 